\title{
Inhibition of Shikimate Kinase and Type II Dehydroquinase for Antibiotic Discovery: Structure-Based Design and Simulation Studies
}

\author{
Concepción González-Bello*
}

Centro Singular de Investigación en Química Biológica y Materiales Moleculares (CIQUS), Universidade de Santiago de Compostela, calle Jenaro de la Fuente s/n, 15782 Santiago de Compostela, Spain

\begin{abstract}
The loss of effectiveness of current antibiotics caused by the development of drug resistance has become a severe threat to public health. Current widely used antibiotics are surprisingly targeted at a few bacterial functions - cell wall, DNA, RNA, and protein biosynthesis - and resistance to them is widespread and well identified. There is therefore great interest in the discovery of novel drugs and therapies to tackle antimicrobial resistance, in particular drugs that target other essential processes for bacterial survival. In the past few years a great deal of effort has been focused on the discovery of new inhibitors of the enzymes involved in the biosynthesis of aromatic amino acids, also known as the

C. Gonzalez-Bello shikimic acid pathway, in which chorismic acid is synthesized. The latter compound is the synthetic precursor of L-Phe, L-Tyr, L-Phe, and other important aromatic metabolites. These enzymes are recognized as attractive targets for the development of new antibacterial agents because they are essential in important pathogenic bacteria, such as Mycobacterium tuberculosis and Helicobacter pylori, but do not have any counterpart in human cells. This review is focused on two key enzymes of this pathway, shikimate kinase and type II dehydroquinase. An overview of the use of structure-based design and computational studies for the discovery of selective inhibitors of these enzymes will be provided. A detailed view of the structural changes caused by these inhibitors in the catalytic arrangement of these enzymes, which are responsible for the inhibition of their activity, is described.
\end{abstract}

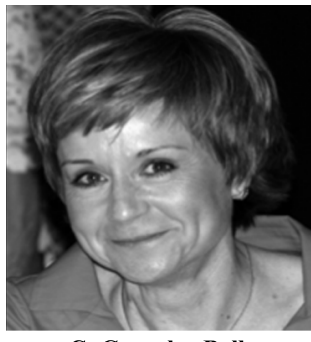

Keywords: Dehydroquinase, Enzyme/inhibitor crystal structures, Essential enzyme motion, Intermediate mimetics, Molecular dynamics simulation studies, Shikimate kinase, Structure-based design, Substrate analogs.

\section{INTRODUCTION}

The increasing development and spread of resistance to current antibiotics have turned ordinary bacterial infections into illnesses that cannot be controlled. Infections from resistant bacteria are now too common and some pathogens have even become resistant to multiple types of antibiotics. The lack of effective antibiotics will undermine our ability to fight infectious diseases and manage the infectious complications common in vulnerable patients undergoing chemotherapy for cancer, dialysis for renal failure, and surgery, especially organ transplantation, for which the ability to treat secondary infections is crucial. In addition, antibacterial drug resistance also has a huge economic impact on individuals as well as healthcare systems and societies $[1,2]$. The European Centre for Disease Prevention and Control (ECDC) estimates that antimicrobial resistance results each year in 25,000 deaths and related costs of over $€ 1.5$ billion in healthcare expenses and productivity losses. However, despite this alarming trend, research into the discovery of new antibiotics by large pharmaceutical companies has dwindled dramatically $[3,4]$. Therefore, there is

\footnotetext{
*Address correspondence to this author at the CIQUS, Universidade de Santiago de Compostela, calle Jenaro de la Fuente s/n, 15782 Santiago de Compostela, Spain; Tel: +34-881-815726, Fax: +34-881-815704;

E-mail: concepcion.gonzalez.bello@usc.es
}

great interest in the discovery of novel drugs and therapies to treat antibiotic-resistant infections and, in particular, of drugs with new mechanisms of action. The most widely used strategy to combat bacterial infections is based on the disruption of the growth cycle by preventing the synthesis and assembly of key components of bacterial processes $[5,6]$. Many drugs that are highly successful in human clinical use mimic a substrate, a transition state or a product of essential enzymes. A detailed knowledge of the catalytic mechanism and the binding determinants of those enzymes can be valuable for the rational design of these mimetics (inhibitors) that can be used as drugs. The increasing availability in recent years of crystal structures of enzyme/inhibitor complexes has undoubtedly been very important to gain a deeper understanding of the enzymatic mechanisms and for the development of potent inhibitors of the selected targets. This success has also benefitted extensively from the recent advances in computational methods that have consolidated their value as important complementary tools that can assist in the elucidation of how these reactions are catalyzed, the binding requirements and the essential motions required for catalysis.

On the other hand, the increasing availability of bacterial genome sequences has created new opportunities for drug discovery. The identification of essential genes and the proteins encoded by them provides an excellent starting point for uncovering novel and important biological processes in 
microorganisms [7]. In fact, current widely used antibiotics are surprisingly targeted at a very small number of key bacterial functions, such as cell wall, DNA, RNA, and protein biosynthesis, and resistance to these antibiotics is widespread and well known [8]. Targeting of new pathways will likely play an important role in the discovery of new antibiotics to combat the growing problem of antibiotic-resistant bacteria. For this purpose, much attention has been devoted to the inhibition of the enzymes involved in the shikimic acid pathway in recent years. This is a biosynthetic route through which erythrose-4-phosphate (1) and phosphoenol pyruvate (2) are converted to chorismic acid (9), the precursor in the synthesis of aromatic amino acids, L-Phe, L-Tyr and L-Thr, and folate cofactors, ubiquinone and vitamins $\mathrm{E}$ and $\mathrm{K}$ (Scheme 1) [9]. The absence of this pathway in mammals, combined with its essential nature in certain microorganisms, makes it an attractive target for the development of new antimicrobial agents [10]. The important features of the shikimic acid pathway have not gone unnoticed by the scientific community and in the past few years a great deal of effort has been focused on the discovery of new inhibitors of the enzymes involved in this route. In this review, we summarize examples of the use of structure-based design and computational studies in the development of selective inhibi- tors of two key enzymes of the shikimic acid pathway that are essential for bacterial survival. The review is focused on the structural changes (binding, motion, conformation) caused by these compounds, which are responsible for their inhibitory activity. This information helps to rationalize the determinants of binding affinity for inhibitors and could provide guidelines for future inhibitor design.

\section{THE SHIKIMIC ACID PATHWAY ENZYMES - ATRACTIVE TARGETS FOR DRUG DISCOVERY}

The enzymes involved in the shikimic acid pathway are present in bacteria, fungi and higher plants, but they are absent in mammals. Some of these enzymes have also been detected in Toxoplasma gondii (which causes malaria) and Plasmodium falciparum extracts, indicating that a complete shikimic acid pathway is present in this parasite $[11,12]$. However, only a single gene encoding the last enzyme of the pathway, chorismate synthase, has been identified conclusively in the genome annotation. It has been suggested that these missing enzymes are either substituted by nonhomologous enzymes that catalyze the same reactions, or that the enzymes are homologous but are too divergent to be identified readily [13]. A good example of the utility of this

\section{SHIKIMIC ACID PATHWAY}
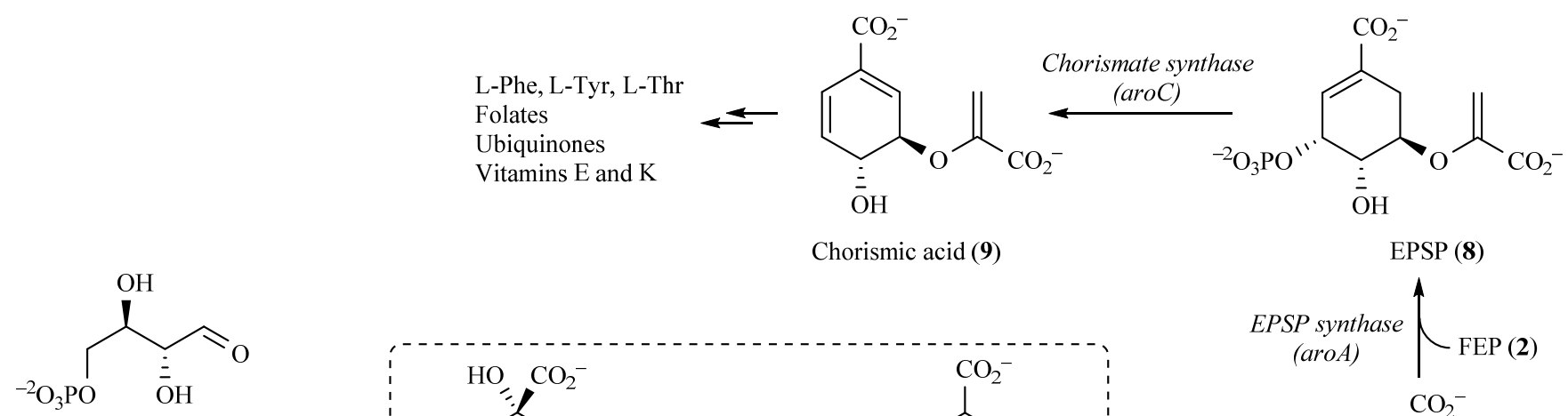

Erythrose 4-phosphate (1)

$+$<smiles>C=C(O[Na])[Po](=O)[O-]</smiles>

FEP (2)

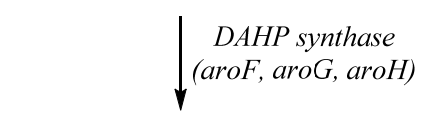

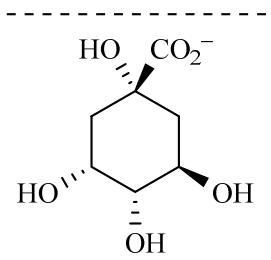

Quinic acid (10)
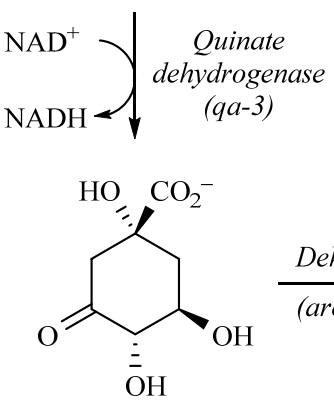

3-Dehydroquinic acid (4) 3-Dehydroshikimic acid (5)

Chorismic acid (9)
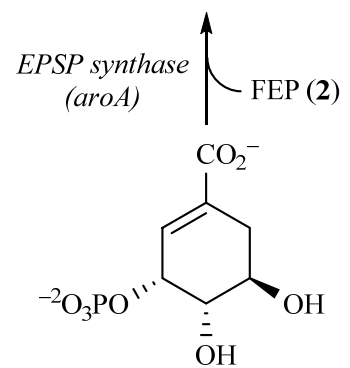

Shikimate 3-phosphate (7)

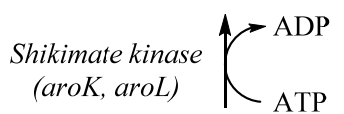

DAHP (3)

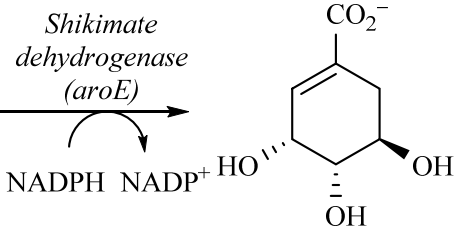

Shikimic acid (6)

Scheme 1. The shikimic acid pathway. The reaction catalyzed by the dehydroquinase enzyme is also part of the quinic acid pathway that converts quinic acid (10) into protocatechuate (11). The genes encoding the enzymes involved in both pathways are also indicated in brackets. 
target is glyphosate [ $N$-(phosphonomethyl)glycine], the active ingredient in the well-known herbicides RoundUp ${ }^{\circledR}$, Zero $^{\circledR}$ and Tumbleweed ${ }^{\circledR}$. Glyphosate is a specific inhibitor of the sixth enzyme of the shikimate pathway [5enolpyruvylshikimate-3-phosphate (EPSP) synthase] with a $K_{\mathrm{i}}$ of $1 \mu \mathrm{M}$ [14] and it has proven to be active in vitro against malaria [11]. Structural studies have shown that glyphosate occupies the phosphoenol pyruvate binding site in the enzyme, mimicking an intermediate state of the ternary enzyme substrate complex $[15,16]$. The shikimic acid pathway starts with the condensation of erythrose-4-phosphate (1) and phosphoenol pyruvate (2) catalyzed by DAHP synthase (7phosphono-2-dehydro-3-deoxyheptonate aldolase, EC 4.1.2.15) to give DAHP (3, 3-deoxy-D-arabinoheptulosonate-7-phosphate), which is converted into 3dehydroquinic acid (4) by dehydroquinate synthase (EC 4.6.1.3) (Scheme 1). This transformation involves an oxidation and a reduction reaction, a phosphate cleavage and an intramolecular aldol condensation using $\mathrm{NAD}^{+}$as cofactor. The next step is the reversible dehydration of 3dehydroquinic acid (4) into 3-dehydroshikimic acid (5) catalyzed by dehydroquinase (EC 4.2.1.10). This transformation is common to the shikimic acid biosynthetic pathway leading to chorismic acid (9) and to the quinic acid catabolic pathway that converts quinic acid (10) into protocatechuate (11) via 3-dehydroquinic acid (4) and 3-dehydroshikimic acid (5) in reactions catalyzed by quinate dehydrogenase (EC 1.1.1.24), dehydroquinase and 3-dehydroshikimate dehydratase (EC 4.2.1.118). The fourth step of the shikimic acid pathway is the reversible reduction of 3-dehydroshikimic acid (5) to shikimic acid (6) using NADPH as cofactor and it is catalyzed by shikimate dehydrogenase (EC 1.1.1.25). The selective phosphorylation of the C3 hydroxyl group of shikimic acid (6) by ATP catalyzed by shikimate kinase (EC 2.7.1.71) then takes place to give shikimate 3-phosphate (7). The enolpyruvyl group of phosphoenol pyruvate (2) is then transferred onto shikimate 3-phosphate (7) to give EPSP (8) and phosphate in a process that is catalyzed by EPSP synthase (EC 2.5.1.19). The last step of the pathway is the elimination of the phosphate group in EPSP (8) catalyzed by chorismate synthase (EC 4.2.3.5) to form chorismic acid (9).

With the exception of the qa-3 gene that encodes for quinate dehydrogenase, all of the gene-encoding enzymes involved in the quinic and shikimic acid pathways have been sequenced. DAHP synthase has three isoenzymes, one for each aromatic amino acid, and three different genes, aroF, aro $G$, and $\operatorname{aroH}$, specifically encode each one of these enzymes, which allows control of the production of each amino acid, Tyr, Phe and Thr, respectively. The enzymes involved in the shikimic acid pathway are particularly attractive targets for the development of new anti-tubercular therapies because six of the seven enzymes, specifically, the ones encoded by aroF, aro $G$, aro $B$, aroD, aro $E$, aroK and aro $A$ genes, are essential for Mycobacterium tuberculosis, which is the causative agent of tuberculosis [17]. Hence, it is not surprising that many developed inhibitors have focused on the disruption of the growth cycle of this bacterium, which will be discussed below. Also remarkable is the potential of these enzymes for the treatment of Helicobacter pylori infections. This bacterium is the causative agent of gastric and duodenal ulcers and has also been classified as a type I car- cinogen. For this bacterium four enzymes of this route are essential, specifically dehydroquinase, shikimate dehydrogenase, shikimate kinase and chorismate synthase (aroQ, aroE, aroK and aroC genes). This review will provide an overview of the most important inhibitors that have been developed against two key enzymes for M. tuberculosis and H. pylori survival, specifically shikimate kinase (aroK) and type II dehydroquinase (aroD/aroQ), which are the fifth and the third enzymes of the shikimic acid pathway.

\section{TARGETING SHIKIMATE KINASE}

Shikimate kinase (SK) catalyzes the stereospecific phosphorylation of the C3 hydroxyl group of shikimic acid (6) by transferring the $\gamma$-phosphate group of ATP to the hydroxyl group to provide shikimate 3-phosphate (7) and ADP. In Escherichia coli there are two types of enzymes, SK I, encoded by the aroK gene, and SK II, encoded by the aroL gene. However, most bacteria only have one type of SK.

The SK enzyme is essential in Mycobacterium tuberculosis, Helicobacter pylori, Acinetobacter baylyi, Haemophilus influenzae, Francisella novicida and Pseudomonas aeruginosa. In addition, it has also been shown that the antimicrobial properties of glyphosate are not only due to EPSP inhibition, as mentioned previously, but also to the high concentrations of shikimic acid and protocatechuate that it causes $[18,19]$. These important features have encouraged diverse research groups to study in detail the substrate binding requirements of this enzyme [20-25]. As a result, several crystal structures of SK, mainly from M. tuberculosis, have been reported, either as binary complexes with ATP, ADP or shikimic acid (6) in the active site, or as tertiary complexes with ADP/shikimic acid (6) or ADP/shikimate 3-phosphate (7) [20-23]. These structures have been an excellent starting point for the structure-based design of inhibitors, which will be discussed below.

\subsection{Substrate Recognition}

SK is a magnesium-dependent enzyme that has two recognition centers, one for shikimic acid (6) and another for the cofactor (ATP), with different key interactions in both cases. SK has three domains (Fig. 1A) [20]: (1) the CORE domain containing five-stranded parallel $\beta$-sheets and the P-loop [residues 9-17 in SK from M. tuberculosis (MtSK)], which forms the binding site for ATP and ADP; (2) the LID domain (residues 112-124 in Mt-SK), which closes over the active site and has residues that are essential for the binding of ATP; and (3) the substrate binding (SB) domain (residues 33-61 in $M t-\mathrm{SK}$ ), which is responsible for the recognition and binding of shikimic acid (6). The SB domain is highly conserved and involves a number of charged residues, specifically Arg136, Arg58, Glu61, Asp34, Arg117 and Lys15, and a lipophilic pocket formed by Phe49, Phe57, Pro118, Gly79, Gly80 and Gly81 (in MtSK). Circular dichroism [21], fluorescence [22] and structural [20-24] studies suggested that ATP first binds to the enzyme and induces a large movement of the LID domain over the active site. Shikimic acid (6) subsequently binds to the active site and the LID domain closes over the active site and brings Arg110 and Arg117 into the ATP and SB domains, respectively [20]. 
A

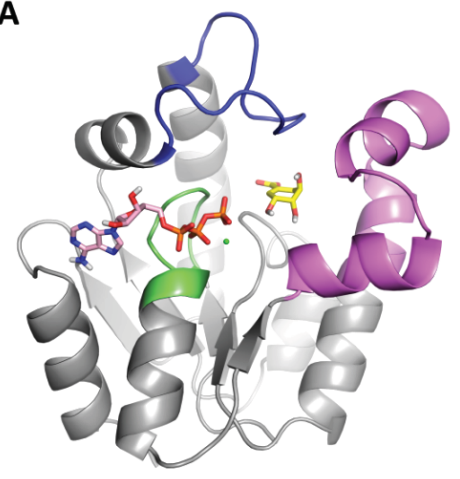

B

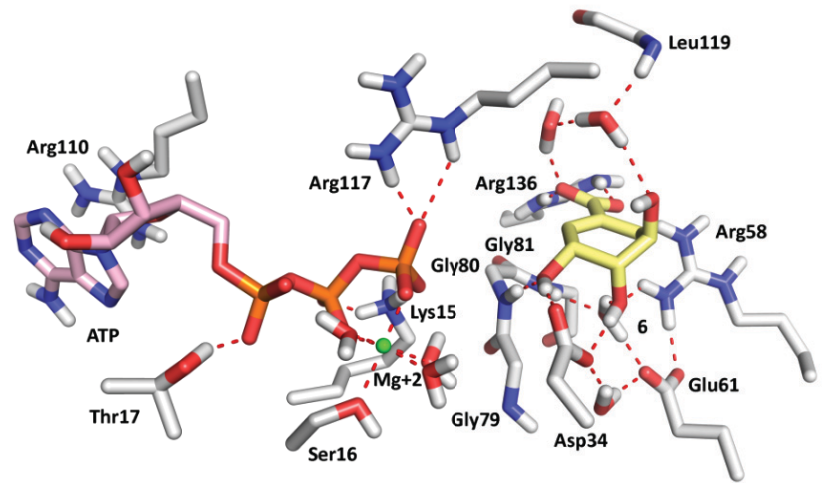

C

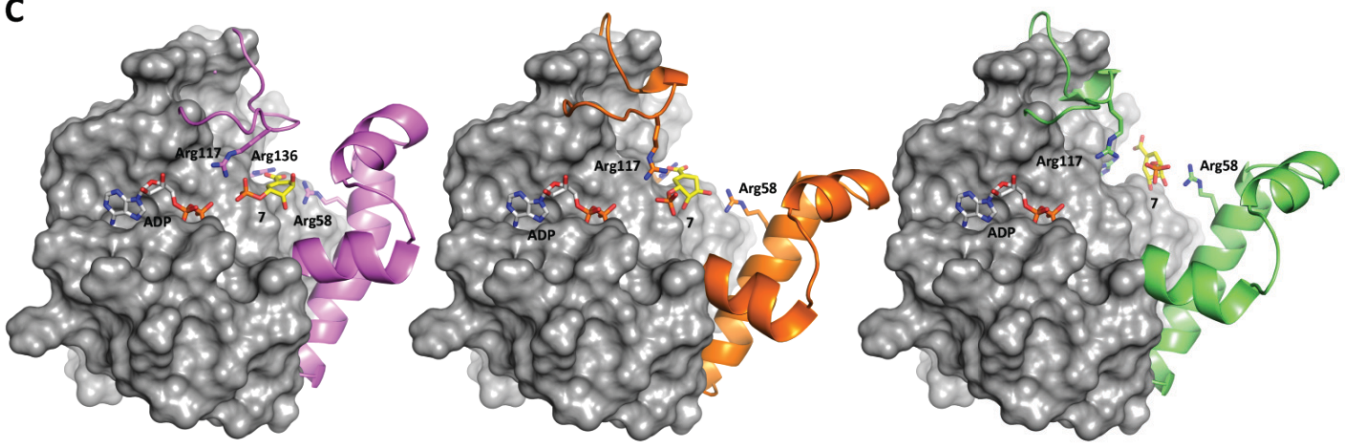

Fig. (1). A) Michaelis complex of $M t$-SK obtained by MD simulation studies [25]. The three domains of SK are shown: CORE (green), LID (blue) and SB (magenta). B) Detail view of the relevant binding interactions of shikimic acid (6) and ATP in the Mt-SK active site. Relevant side chain residues are shown and labeled. Hydrogen bonding interactions between the substrates and the enzyme are shown as dashed red lines. C) Representative snapshots of the shikimate-3-phosphate (7) release from the active site of $M t$-SK obtained by MD simulations (10 ns). Note the large conformational changes of the LID and the $\alpha$-helices $\alpha 3$ and $\alpha 2$ of the SB binding domains during product release.

The available crystal structures of SK with shikimic acid (6) in the active site show that the substrate is strongly anchored to the active site by a salt bridge with the guanidinium group of Arg136 and by hydrogen bonding between the side chain of the essential Asp34 residue and the C4 hydroxyl group (Fig. 1B). Remarkably, shikimic acid (6) binds to the enzyme in an unusual and unstable conformation for a cyclohexene ring with two of the three hydroxyl groups ( $\mathrm{C} 4$ and $\mathrm{C5}$ ) in an axial arrangement. By forcing the axial disposition of the $\mathrm{C} 4$ and $\mathrm{C} 5$ hydroxyl groups, the enzyme controls the equatorial disposition of the $\mathrm{C} 3$ hydroxyl group and allows its selective phosphoryl-transfer reaction. The exquisite control of the axial position of the $\mathrm{C} 4$ hydroxyl group is achieved by hydrogen-bonding interactions with the essential Asp34 [24], the conserved Gly80 residues and a water molecule, the position of which is frozen by the conserved residues Glu61, Arg58 and Gly80. The axial arrangement of the hydroxyl group in $\mathrm{C} 5$ is achieved by two water molecules that form a bridge between the carboxylate group and the C5 hydroxyl group. These water molecules are always located in a nonpolar pocket generated by the conserved Phe 49 and Phe57 residues located in $\alpha$-helices $\alpha 3$ and $\alpha 4$, which - together with $\operatorname{Arg} 117$ - helps to seal the active site from the solvent environment.

\subsection{Essential Motions for Catalytic Turnover}

Molecular dynamics (MD) simulations performed with the Michaelis complex (Mt-SK/ADP/7 ternary complex) revealed that the strong salt-bridge interaction between the phosphate group in 7 and the guanidinium group of Arg117 triggers the release of the product from the active site [25] (Fig. 1C). By pulling on the phosphate group in 7, Arg117 causes the breakdown of the favorable interactions of the product with the active site residues, particularly the saltbridge interaction between the $\mathrm{C} 1$ carboxylate group and the guanidinium group of Arg136. As a consequence, a conformational change in the product and a large movement of the SB domain takes place (up to $10 \AA$ ). During product release, the LID domain also undergoes large movements (up to $6 \AA$ ) to allow the Arg117 and Arg136 side chains to expel the product from the active site.

MD simulation studies also highlighted that there are four key structural factors required for the catalysis [25]: (1) the $\mathrm{C} 4 / \mathrm{C} 5$ diaxial conformation of shikimic acid (7); (2) a closed form of the LID domain to allow activation of the $\gamma$ phosphate of ATP and stabilization of the transition state by the guanidinium group of the Arg117 side chain; (3) a closed form of the SB domain in order to bring the substrates together for the phosphoryl-transfer reaction and to isolate the substrate within an apolar cavity; (4) flexible LID and SB domains for product release. These key points have been the starting point for the structure-based design of mimetics of the natural substrate, which will be discussed below.

\subsection{Shikimate Kinase Inhibitors}

\subsubsection{Substrate Mimetics}

Considering that the P-loop, which forms the binding site for ATP and ADP, is rather conserved in many ATP- or GTP-binding proteins, several mimetics of shikimic acid (6) 
were designed for specific binding to the SB binding site of this kinase [25]. Based on the aforementioned structural requirements, compounds 12-13 were designed to fix the diaxial conformation of the $\mathrm{C} 4$ and $\mathrm{C} 5$ substituents in the natural substrate (Fig. 2). Both compounds proved to be reversible competitive inhibitors of the $M t$-SK with $K_{\mathrm{i}}$ values of 62 and $46 \mu \mathrm{M}$, respectively - in both cases below the $K_{\mathrm{m}}$ of the enzyme $(544 \mu \mathrm{M})$.<smiles>O=C(O)C1=C[C@@]2(O)COC(O2)[C@H]1O</smiles>

12<smiles>N[C@H]1C=C(C(=O)O)C[C@H](O)[C@H]1O</smiles>

15<smiles>O=C(O)C1=C[C@@]2(O)COC(C2)[C@H]1O</smiles>

13<smiles>C[C@@H]1C=C(C(=O)O)C[C@H](O)[C@H]1O</smiles>

$16 \mathrm{Z}=\mathrm{NH}_{2}$ $17 \mathrm{Z}=\mathrm{OH}$<smiles>CC1(C)OC2C(C(=O)O)=C[C@@H](O)[C@H](O)C2O1</smiles>

14<smiles>O=C(O)C1=C[C@@H](O)[C@H](O)[C@H](O)[C@H]1O</smiles>

18
Fig. (2). Competitive reversible inhibitors of $M t-\mathrm{SK}$.

The crystal structure of $M t$-SK in complex with ADP and compound 12 (PDB entry 4BQS, $2.15 \AA$ ) reveals that the cyclohexene ring of inhibitor $\mathbf{1 2}$ occupies approximately the same site and has similar binding interactions as the natural substrate (Fig. 3A). Inhibitor $\mathbf{1 2}$ provides a tidy closed form of the active site and prevents the opening of the SB binding domain, which is required for turnover. MD simulation studies suggested that the reduction of the double bond of the C3-C5 ether bridge in 12 enhances the lipophilic interactions of this bridge with the conserved residues Arg117 and Pro118. This more effective reduction of the flexibility of the LID domain might also explain its higher inhibitory potency.

The (3R)- (15) and (3S)-3-aminoshikimic acids (16) were also designed as mimetics of the natural substrate. Both compounds proved to be reversible competitive inhibitors of the $M t$-SK enzyme with $K_{\mathrm{i}}$ values of 62 and $65 \mu \mathrm{M}$, respectively. Docking and MD simulation studies showed that both compounds would interact with the $\gamma$-phosphate of ATP through a strong electrostatic interaction and they would cause a dramatic reduction in the flexibility of the LID and the SB domains (Fig. 3B and C).

6-Hydroxy derivatives $\mathbf{1 4}$ and $\mathbf{1 8}$ proved to be weak competitive reversible inhibitors of the enzyme with $K_{\mathrm{i}}$ values of 1050 and $792 \mu \mathrm{M}$, respectively. The MD simulation studies carried out with $(6 R)$-6-hydroxyshikimic acid (18) showed that this compound caused significant changes in the water network and caused an opening of the SB domain by nearly $6 \AA$. During the simulation the ligand also undergoes a conformational change to the thermodynamically more stable conformation, i.e., with $\mathrm{C} 4$ and $\mathrm{C} 5$ hydroxyl groups in the pseudo-equatorial conformation. This binding conformation of $\mathbf{1 8}$ and the greater flexibility of the SB domain seem to be responsible for the lower inhibitory potency of this compound.

In summary, the inhibitory properties and binding mode of compounds 12-18 reveal that the fixation of the diaxial conformation of the $\mathrm{C} 4$ and $\mathrm{C} 5$ hydroxyl groups recognized by the enzyme is a promising strategy for inhibition because it causes a dramatic reduction of the flexibility of the LID and shikimic acid binding domains. Moreover, the (3R)- (15) and (3S)-3-hydroxyshikimic acids (16) are also good scaffolds for the future generation of inhibitors.

\subsubsection{Inhibitors Identified by Screening}

Compounds that target the SK enzyme have also been discovered by screening. For example, Simithy et al. used LC-MS and a library of about 400 antimycobacterial compounds, which were previously found by the NIH Tuberculosis Antimicrobial Acquisition and Coordination Facility (TAACF), to identify several compounds that inhibit $M t$-SK [26]. The most active compounds were 19, 20 and 21, with $\mathrm{IC}_{50}$ values between 1.9 and $3.8 \mu \mathrm{M}$, and these contain an oxadiazole-amide or a 2-aminobenzothiazole moiety in their structure (Fig. 4). The authors used sulfonamide 22, with an $\mathrm{IC}_{50}$ value of $0.2 \mu \mathrm{M}$, previously described by Bandodkar et al. [27], as a positive control for the assay.

Han et al. carried out the high-throughput screening of a library of about 3000 compounds and discovered two inhibitors of SK from Helicobacter pylori ( $\mathrm{Hp}$-SK), namely compounds 23 and 24 , with $\mathrm{IC}_{50}$ values of 5.5 and $6.4 \mu \mathrm{M}$, respectively (Fig. 4) [28]. Cheng et al. also identified the
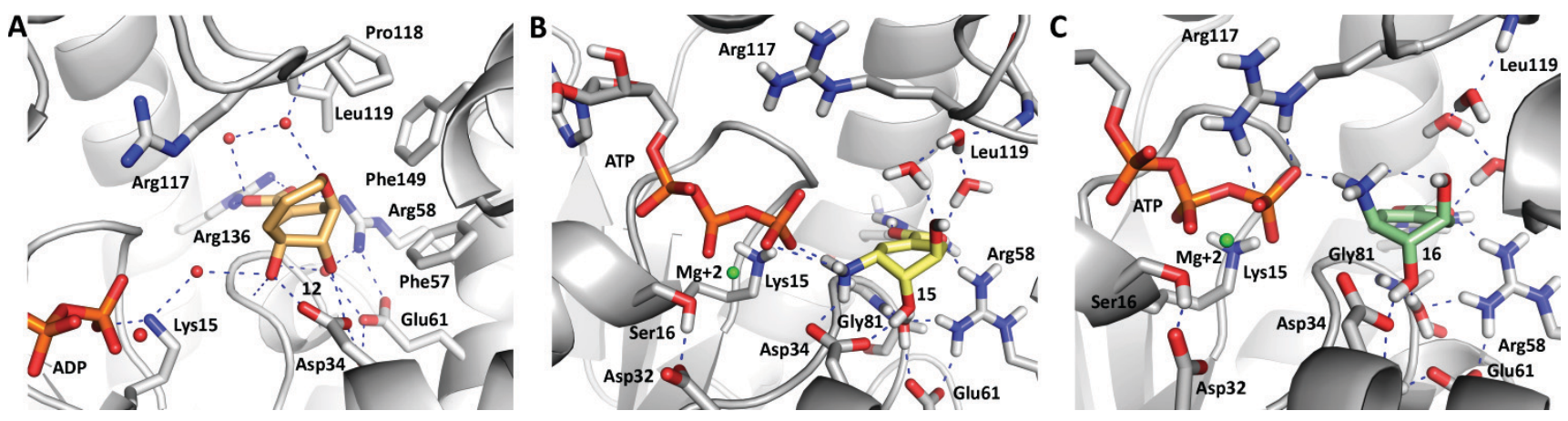

Fig. (3). A) Crystal structure of the ternary complex $M t$-SK/ADP/12 (orange, PDB entry 4BQS). B,C) Binding mode of (3R)-3aminoshikimic acid (15, yellow) and (3S)-3-aminoshikimic acid (16, green) obtained by MD simulation studies. Relevant side chain residues are shown and labeled. Polar (blue) interactions between ligands and the $M t$-SK are shown. 


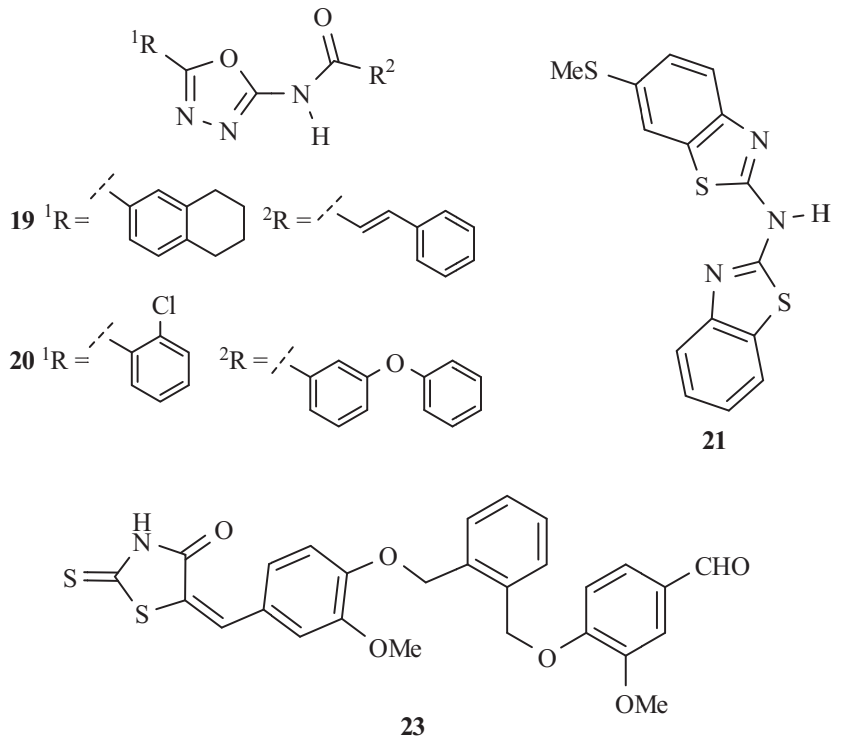<smiles>Cc1cc(O)n(-c2ccc(NS(=O)(=O)c3cc(Cl)cc(Cl)c3)cn2)n1</smiles><smiles></smiles>

Fig. (4). Selected examples of SK inhibitors identified by screening.

naphthalene-2-sulfonate 25 , which had an $\mathrm{IC}_{50}$ value of 4.9 $\mu \mathrm{M}$ (Fig. 4) [29]. The authors also solved the crystal structure of E114A $\mathrm{Hp}$-SK variant enzyme in complex with $\mathbf{2 5}$ (PDB entry 3N2E, $2.53 \AA$ ) (Fig. 5). This structure reveals that the ligand prevents the closure of the active site for catalysis by causing a large conformational change in the LID domain. Specifically, the ligand establishes two strong cation- $\pi$ interactions, one with the conserved residue Arg132, which is responsible for the $\mathrm{C} 1$ carboxylate recognition of the substrate/product, and another with the essential Arg116, which is key for ATP binding and product release and it has been suggested that this acts as a Lewis acid during the catalysis [25]. In addition, a strong electrostatic interaction between the guanidinium moiety of Arg116 and one of the sulfonate groups fixes the ligand between the LID and the SB domain.

Moreover, the availability of several crystal structures of the SK enzymes, mainly from $M$. tuberculosis and $H$.

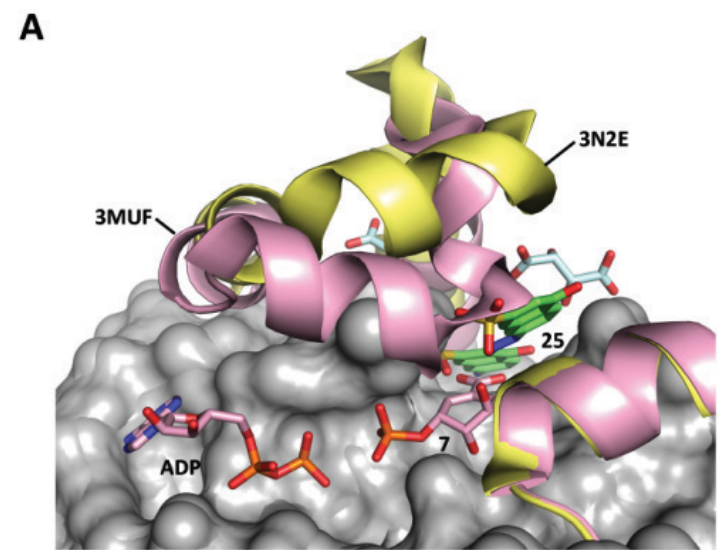

pylori, have encouraged diverse virtual screening studies for the identification of potential inhibitors of these enzymes [30, 31].

\section{TARGETING DEHYDROQUINASE}

Dehydroquinase (3-dehydroquinate dehydratase, DHQ, EC 4.2.1.10) catalyzes the reversible dehydration of 3dehydroquinic acid (4) to form 3-dehydroshikimic acid (5) (Scheme 1). There are two distinct types of enzymes, known as type I (DHQ1, aroD gene) and type II (DHQ2, aroD/aroQ gene), which have different biochemical and biophysical properties and show no sequence similarity [32,33]. DHQ1, which is found in plants, fungi and bacterial species such as Escherichia coli, Staphylococcus aureus and Salmonella typhi, is exclusively biosynthetic and is a heat-labile dimer with a subunit of around $27 \mathrm{KDa}$. DHQ1 is a class I aldolase enzyme that catalyzes the syn elimination of water in 4 by a multi-step mechanism that involves the formation of a Schiff

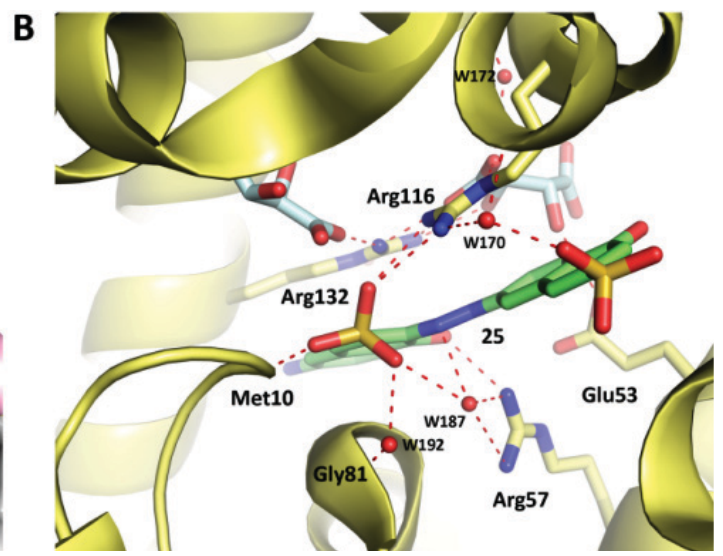

Fig. (5). A) Comparison of the complexes $H p$-SK/ADP/7 (PDB entry 3MUF) $v s H p-S K / 25$ (PDB entry $3 \mathrm{~N} 2 \mathrm{E}$ ). The LID and SB domains of both crystal structures are highlighted (yellow and pink, respectively). Note how compound $\mathbf{2 5}$ causes a large conformational change in the LID domain, thus avoiding its closure for catalysis. B) Binding interactions of compound $\mathbf{2 5}$ (green) in the binary complex $H p$-SK/25 (yellow, PDB entry 3N2E). L-Tartaric acid molecules (blue) from crystallization conditions are also shown. Polar (red) interactions between $\mathbf{2 5}$ and the $H p$-SK are shown as dashed lines. Relevant residues are shown and labeled. 
base. It has been suggested that DHQ1 may act as a virulence factor in vivo as the deletion of the aroD gene affords satisfactory live oral vaccines, that provides monkeys with protection against oral challenge with live S. flexneri $2457 \mathrm{~T}$ [34-37]. In contrast, DHQ2, which has both biosynthetic and catabolic roles and is a heat-stable dodecamer (tetramer of trimers) with a subunit of $16-18 \mathrm{KDa}$, catalyzes the anti elimination of water in 4 . In contrast to DHQ1, the reaction mechanism of DHQ2 does not involve any covalent attachment of the substrate to the enzyme through Schiff base formation. DHQ2 is essential in important pathogenic bacteria such as Mycobacterium tuberculosis (aroD gene) and Helicobacter pylori (aroD/aroQ gene) [17].

The fact that two enzymes have evolved to catalyze the same reaction by entirely different mechanisms and stereochemical courses [38] has been used for the design of compounds that specifically inhibit either DHQ1 or DHQ2 enzymes. Of the two, particular attention has been paid to the inhibition of the DHQ2 enzyme as a potential target for the development of anti-tubercular drugs as well as for the treatment of infectious diseases caused by $H$. pylori. As a result, numerous potent inhibitors of this target have been developed. The resolution of crystal structures of several DHQ2/inhibitor binary complexes has undoubtedly been very important for this success, not only for the development of inhibitors of improved activity but also to gain a deeper understanding of its anti dehydration mechanism and the binding requirements of the DHQ2 enzyme.

\subsection{Mechanism and Substrate Binding}

The DHQ2 mechanism involves the loss of the more acidic pro- $S$ hydrogen from $\mathrm{C} 2$ in 4 (Scheme 2). An arginine [Arg17/Arg19 in DHQ2 from H. pylori (Hp-DHQ2) and from $M$. tuberculosis (Mt-DHQ2), respectively] and a tyrosine (Tyr22/Tyr24 in $H p$-DHQ2 and $M t$-DHQ2, respectively) have been identified by chemical modification and site-directed mutagenesis studies as being essential for enzyme activity $[39,40]$. Both residues are on the flexible loop that closes over the active site upon substrate binding. In the absence of any crystal structure and based on kinetic isotope effects and $\mathrm{pH}$ profile studies carried out on $M t$-DHQ2 and Aspergillus nidulans DHQ2 (An-DHQ2), Harris et al. [41] suggested that the elimination proceeds by a stepwise $\mathrm{E}_{1} \mathrm{CB}$ mechanism via enolate intermediate 26 (Scheme 2). Subsequent resolution of the DHQ2 from Streptomyces coelicolor (Sc-DHQ2) with an inhibitor in the active site (PDB entry 1GU1, $1.8 \AA$ ) by Roszak et al. [42] allowed a detailed description of the active site and provided a good knowledge of the specific functions of individual amino acid residues. The substrate is strongly bound to the active site by a series of hydrogen bonding interactions through the carboxylate group and the three hydroxyl groups. In particular, the carboxylate binding pocket is a key part in the recognition and this gives rise to four strong hydrogen bonding interactions involving the main chain amide NH groups of Ile102 and Ser103, the side chain $\mathrm{OH}$ group of Ser103 and the side chain amide of the conserved Asn75 (in Mt-DHQ2). The latter residue also acts by correctly positioning the $\mathrm{C} 1$ hydroxyl group to accept a proton from the conserved His 101 . In addition, the C5 hydroxyl group interacts by hydrogen bonding with the conserved His81 and Arg112 residues and Asp88* forms the major interaction with the $\mathrm{C} 4$ hydroxyl group. The reported crystal structure reveals two key facts: (a) the absence of any suitable residue that could stabilize an enolate intermediate; (b) the presence of a conserved water molecule (henceforth WAT1) in close proximity to the position that would be occupied by the enolate intermediate 26. On the basis of these structural considerations, the authors suggested that the reaction is initiated by the essential tyrosine, which removes the pro-S hydrogen from $\mathrm{C} 2$ of $\mathbf{4}$ to afford an enol intermediate. The final step is the acid-catalyzed elimination of the $\mathrm{C} 1$ hydroxyl group - a reaction mediated by the conserved histidine His102/His101 (in $H p$-DHQ2 and $M t$-DHQ2, respectively) acting as a proton donor. However, the suggested formation of an enol rather than an enolate intermediate did not explain the observed solvent isotope effects and proton inventory of $M t$-DHQ2, in which there is a single proton
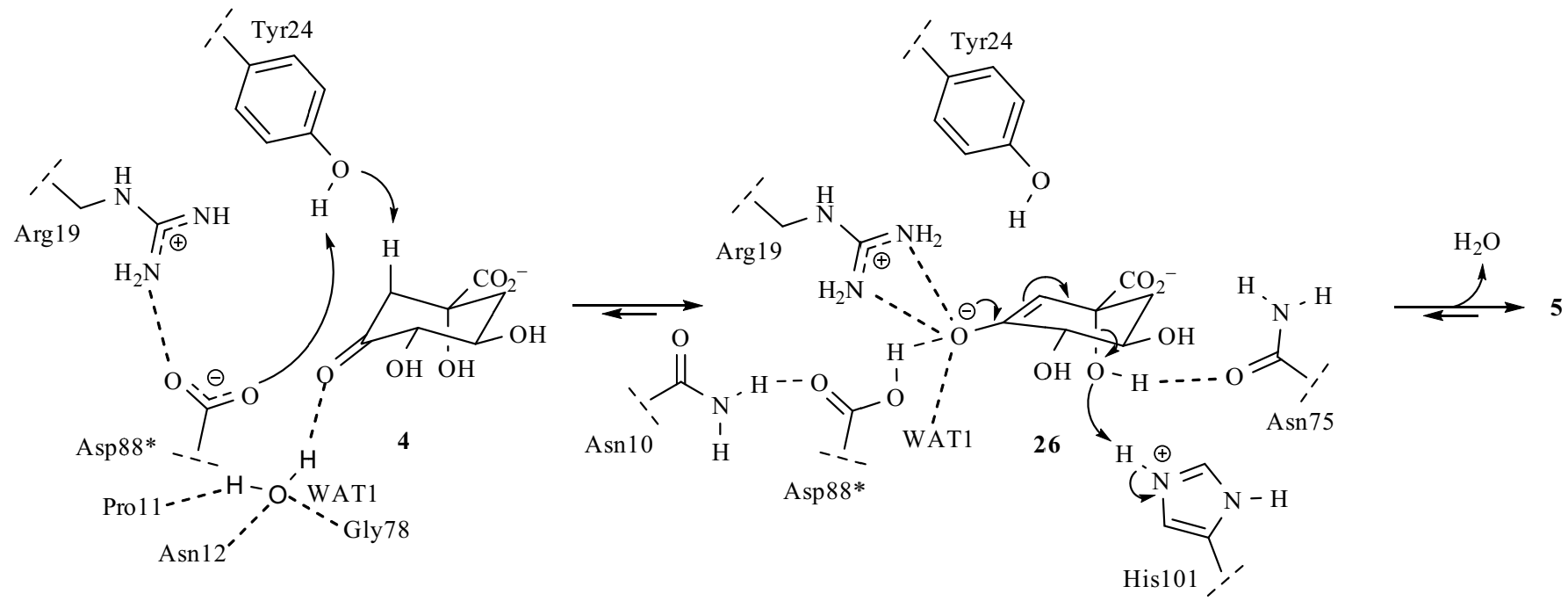

Scheme 2. Proposed mechanism for the reaction catalyzed by Mt-DHQ2. Relevant residues are indicated and labeled. Hydrogen bonds are shown as dashed lines. Note how Asp88* from a neighboring enzyme subunit is responsible for the generation of the catalytic form of the essential tyrosine (tyrosinate) and Arg 19 stabilizes the enolate intermediate 26. 
contributing to this effect [41]. On the basis of results from quantum mechanical (QM) calculations using different Hamiltonians on Sc-DHQ2, Blomberg et al. [43] subsequently suggested again the formation of enolate intermediate $\mathbf{2 6}$ because of its significantly lower energy compared to that of the enol intermediate.

More recently, hybrid QM/MM (quantum mechanics/molecular mechanics) calculations and biochemical studies have provided a good understanding of the catalytic mechanism in atomic detail and provided details of the required motions for the catalytic turnover [44]. Remarkably, these studies clarified how the catalytic form of the essential tyrosine (tyrosinate) is formed and the role of the essential arginine in the enzymatic catalysis. These studies showed that an aspartate from the neighboring enzyme subunit (Asp89*/Asp88* in $\mathrm{Hp}$-DHQ2 and $\mathrm{Mt}$-DHQ2, respectively; residues from this subunit are marked with an asterisk) is the residue responsible for the deprotonation of the essential tyrosine to afford the catalytic tyrosinate, which triggers the enzymatic process (Fig. 6). The essential nature of this residue was corroborated by site-directed mutagenesis studies. For $\mathrm{Hp}$-DHQ2, this reaction takes place with the assistance of a water molecule (Fig. 6B), while for $M t$-DHQ2 the tyrosine is directly deprotonated by the aspartate residue (Fig. 6A). These results are consistent with the solvent isotope effects and proton inventory [44], which shows that there are at least two protons involved in the reaction, one associated with the elimination step and another/others involved in tyrosine deprotonation. These studies also show that the guanidinium group of Arg17/Arg19 must be close to the essential tyrosine side chain for catalysis. In this arrangement, the arginine controls the appropriate orientation of the tyrosine, which is roughly perpendicular to the cyclohexane ring of the natural substrate, through a cation- $\pi$ interaction and contributes to decreasing the $\mathrm{pKa}$ of the phenol group. The tyrosinate removes the axial hydrogen from $\mathrm{C} 2$ of $\mathbf{4}$ to give an enolate intermediate 32 (Fig. 6C), which is stabilized by the positively charged side chain of the essential Arg17/Arg19 and by a hydrogen bond between the neutral aspartate Asp89*/Asp88* and the conserved water molecule WAT1.
The presence of WAT1 in many crystal structures and its role in the enzymatic mechanism have been widely discussed. WAT1 interacts through hydrogen bonding with a conserved asparagine (Asn10/Asn 12 in $\mathrm{Hp}$-DHQ2 and $\mathrm{Mt}$ DHQ2, respectively), the carbonyl group of a conserved proline (Pro9/Pro11 in $\mathrm{Hp}$-DHQ2 and $M t$-DHQ2, respectively) and the main-chain amide of a glycine or an alanine (Ala79/Gly78 in $H p$-DHQ2 and $M t$-DHQ2, respectively). Initially, it was proposed that WAT1 would be involved in the enzymatic mechanism [42]. However, QM/MM studies suggest that WAT1 would be mainly involved in the stabilization of the substrate and enol intermediate 32 [44].

\subsection{Reversible Competitive Inhibitors}

Based on the reaction mechanism, a large number of competitive reversible inhibitors have been developed $[45,46]$. In general, these compounds are either analogs of the natural substrate or mimetics of the enolate intermediate 26. The structural changes (binding, motion, conformation) caused by these compounds, which are responsible for their inhibition activity, are discussed below.

\subsubsection{Substrate Analogs}

Reasoning that the reaction catalyzed by DHQ2 involves the abstraction of the axial hydrogen from $\mathrm{C} 2$ of $\mathbf{4}$, a good strategy to inhibit the enzyme proved to be the substitution of the axial hydrogen by a group that is able to interact with the base responsible for this process, i.e., the tyrosine. Nevertheless, we have shown that substrate analogs equatorially substituted at $\mathrm{C} 2$ by benzyl groups are also good reversible competitive inhibitors of the enzyme, since the methylene group of the benzyl group allows the aromatic ring of the inhibitor to be located close to the tyrosine ring. Indeed, the substitution of either the pro- $S$ or pro- $R$ hydrogen at $\mathrm{C} 2$ of 4 by a functionalized benzyl group, compounds 27 and $\mathbf{2 8}$, respectively, provides good reversible competitive inhibitors of the DHQ2 enzyme (Fig. 7) [47,48].

The resolution of the crystal structures of the binary complexes between $M t$-DHQ2 and $H p$-DHQ2 and one of the
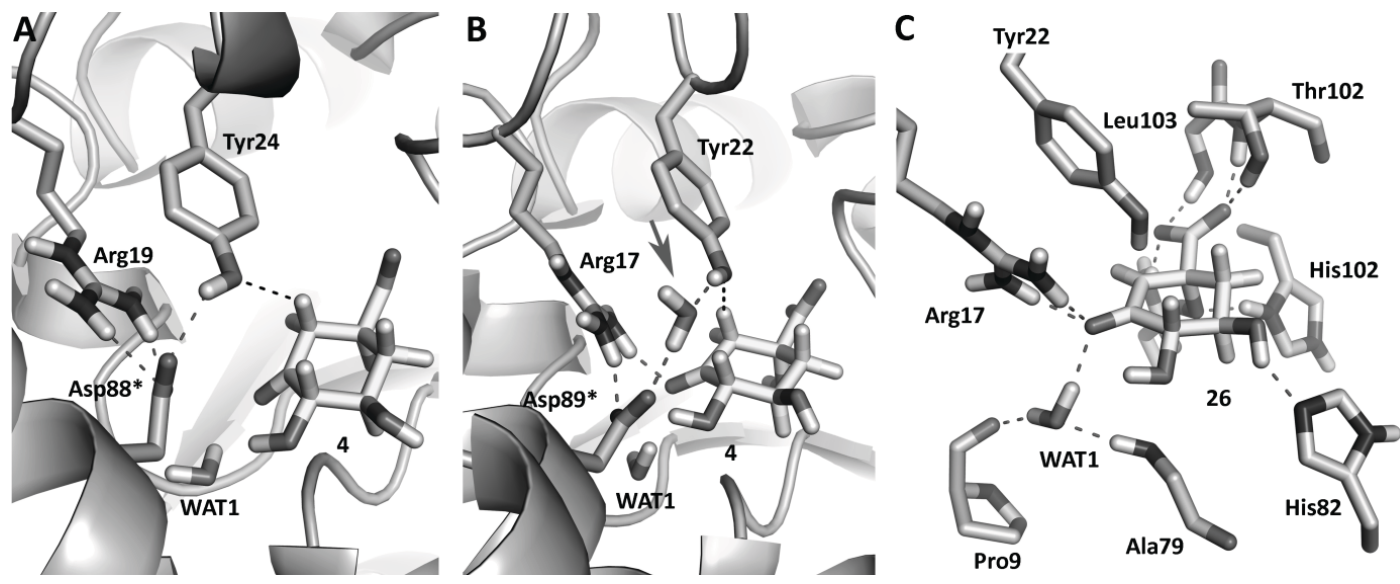

Fig. (6). Detail view of the DHQ2 Michaelis complexes and enolate intermediate 26 geometries obtained by QM/MM studies: A) Mt-DHQ2 Michaelis complex. B) $H p$-DHQ2 Michaelis complex. C) $H p$-DHQ2 enolate intermediate 26 geometry. Note how Asp88*/Asp89* from a neighboring enzyme subunit is responsible for the generation of the catalytic form of the essential tyrosine (tyrosinate). For $H p$-DHQ2, this reaction takes place with the assistance of a water molecule. Relevant residues and water molecules are indicated and labeled. Hydrogen bonds and key distances are shown. 
most potent inhibitors of the $2 R$-substituted derivatives $\mathbf{2 8}$, i.e., 4-methoxybenzyl derivative $\mathbf{2 8 b}$, which has $K_{\mathrm{i}}$ values of $26 \mathrm{nM}$ and $170 \mathrm{nM}$, respectively, has been very important in understanding the role of the aromatic moiety for inhibition (Fig. 8A and C) [49]. These crystal structures reveal that these compounds inhibit DHQ2 because their aromatic functional groups block the catalytic arrangement of the tyrosine and the arginine, i.e., it avoids the cation- $\pi$ interaction between the guanidinium group of Arg17/Arg19 and the phenol group of the tyrosine side chain. In particular, the aromatic moiety of $\mathbf{2 8 b}$ interacts with the catalytic tyrosine by $\pi$-stacking and, more importantly, expels the arginine sidechain from the active site.

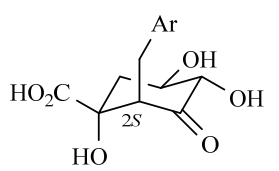

27

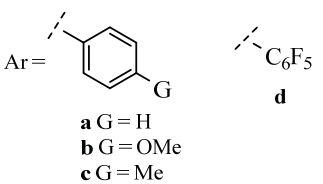

c $\mathrm{G}=\mathrm{Me}$

\begin{tabular}{|c|c|c|c|}
\hline $27 / 28$ & M. tuberculosis ${ }^{a}$ & H. pylori ${ }^{b}$ & S. coelicolor ${ }^{c}$ \\
\hline $27 a$ & 90 & 1180 & 1050 \\
\hline $27 b$ & 90 & 970 & 150 \\
\hline $27 \mathrm{c}$ & 100 & 1420 & 340 \\
\hline 27d & 74 & 970 & 7 \\
\hline $27 \mathrm{e}$ & 56 & 900 & 38 \\
\hline $28 \mathrm{a}$ & 100 & 1400 & 1550 \\
\hline $28 b$ & 26 & 170 & 34 \\
\hline $28 \mathrm{c}$ & 89 & 250 & 22 \\
\hline 28d & 47 & 2600 & 242 \\
\hline $28 \mathrm{e}$ & 28 & 160 & 4 \\
\hline
\end{tabular}

${ }^{a} \mathrm{pH} 7.0,25^{\circ} \mathrm{C}, 50 \mathrm{mM}$ Tris.HOAc $\left(K_{\mathrm{m}}=15 \mu \mathrm{M}\right) .{ }^{b} \mathrm{pH} 7.0,25^{\circ} \mathrm{C}, 50 \mathrm{mM}$ Tris. $\mathrm{HCl}\left(K_{\mathrm{m}}\right.$ $=448 \mu \mathrm{M}) \cdot{ }^{\mathrm{C}} \mathrm{pH} 7.0,25^{\circ} \mathrm{C}, 50 \mathrm{mM}$ Tris. $\mathrm{HCl}\left(K_{\mathrm{m}}=250 \mu \mathrm{M}\right)$.

Fig. (7). 2-Benzyl-3-dehydroquinic acids 27-28, competitive reversible inhibitors of DHQ2 enzyme. $K_{\mathrm{i}}(\mathrm{nM})$ values of compounds 27-28 against DHQ2 from different sources are shown.
Moreover, MD simulations suggest that the benzyl groups of ligands $\mathbf{2 8}$ inactivate the enzyme by causing a significant conformational change of the substrate-covering loop and a dramatic reduction of its flexibility, which is essential for the function of the enzyme [49]. In fact, this approach allowed the resolution of the M. tuberculosis loop containing residues 20-25 for the first time (Fig. 8A, PDB entry $2 \mathrm{XB} 8,[49])$. It is important to highlight that the $2 R$ substituted derivatives $\mathbf{2 8}$ still contain the axial hydrogen that could be removed by the essential tyrosine, the residue that triggers the dehydration reaction.

For the $H p$-DHQ2 enzyme and regardless of the type of substituent of the aromatic ring, the binding mode of the $2 S$ - 27 and 2R-2-benzyl derivatives $\mathbf{2 8}$ are quite similar, which could explain the similar inhibition constants obtained (Fig. 8C and D) $[49,50]$. In all cases, the essential Arg17 is expelled from the active site and faces away from the essential Tyr22. In contrast, for the $M t$-DHQ2 enzyme there are significant differences in the binding mode of these compounds depending on the type of substituent on the aromatic ring. Thus, all of the inhibitors cause a dramatic reduction of the loop flexibility, albeit by a different mechanism (Fig. 8C and D) [49,50]. For instance, the perfluorobenzyl derivative $\mathbf{2 7} \mathbf{d}$ causes the complete closure of the active site through the formation of a strong $\pi-\pi$ stacking interaction with the aromatic ring of Tyr24 and a favorable electrostatic interaction with the guanidinium group of Arg19. In contrast, the 4-methoxybenzyl derivative $\mathbf{2 7 b}$ favors a more open conformation of the loop, with Arg19 facing out of the active site.

\subsubsection{Enolate Intermediate Mimetics}

Bearing in mind the fact that the elimination mechanism of the DHQ2 enzymes proceeds via enol intermediate 26, which is characterized by ring-flattening between the $\mathrm{C} 2-\mathrm{C} 3$ bond, Frederickson et al. [51] designed the first mimetic of the enolate intermediate, 2,3-dehydroquinic acid (29), which proved to be a reversible competitive inhibitor of $M t$-DHQ2 and $S c$-DHQ2 with $K_{\mathrm{i}}$ values of $200 \mu \mathrm{M}$ and $30 \mu \mathrm{M}$, respectively (Fig. 9). These authors subsequently replaced hydrogen $\mathrm{H} 3$ of $\mathbf{2 9}$ by a fluorine atom, compound $\mathbf{3 0}$, in order to mimic the high electron density generated at C3 during the course of the reaction $[52,53]$. This substitution provides a more potent analog of 29, with $K_{\mathrm{i}}$ values of $10 \mu \mathrm{M}$ and 15 $\mu \mathrm{M}$, respectively.
A

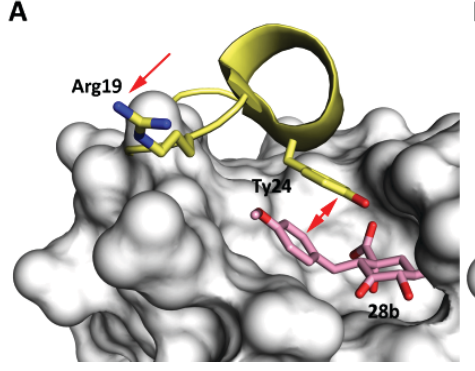

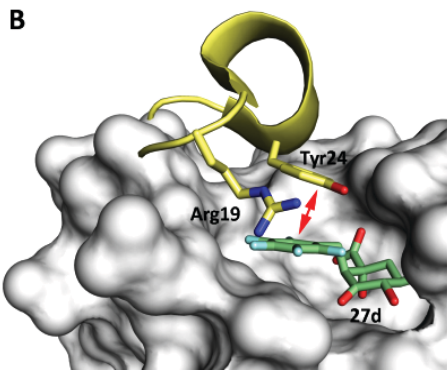

C

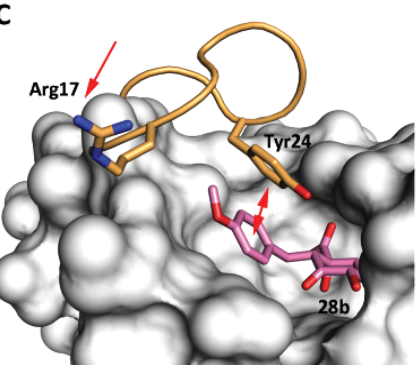

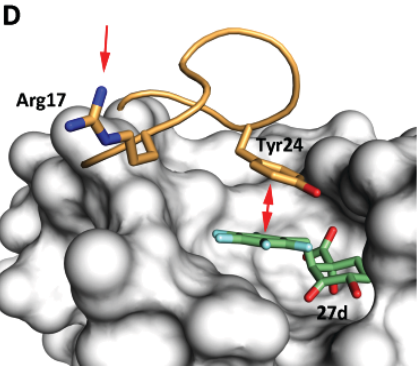

Fig. (8). Conformational changes of the substrate-covering loop observed in crystal structures of DHQ2 in complex with 2-benzyl-3dehydroquinic acids 27d and 28b. A) $M t$-DHQ2/28b (PDB entry 2XB8, $2.4 \AA$ ). B) $M t$-DHQ2/27d (PDB entry 4B6P, $2.3 \AA$ ). C) $H p$ DHQ2/28b (PDB entry 2XB9, $2.75 \AA$ ). D) Hp-DHQ2/27d (PDB entry 4B6S, $1.9 \AA$ ). The substrate-covering loop (yellow, light orange) and relevant side chain residues are shown and labeled. 


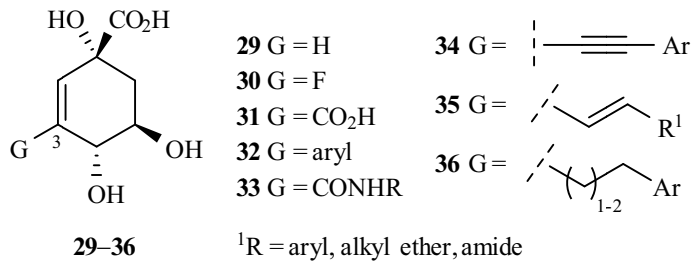

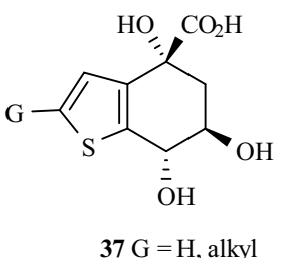

$37 \mathrm{G}=\mathrm{H}$, alkyl

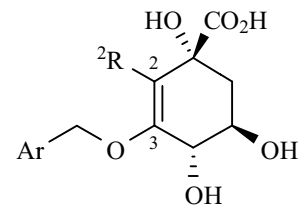

$38^{2} \mathrm{R}=\mathrm{H}$

$39{ }^{2} \mathrm{R}=$ alkylaryl

Fig. (9). Mimetics of the enolate intermediate 29 that are competitive reversible inhibitors of the DHQ2 enzyme.

The important observation that compounds with a double bond between $\mathrm{C} 2-\mathrm{C} 3$ bind in the manner predicted for transition state mimetics, as revealed by the crystal structure of $\mathrm{Sc}$ DHQ2 with 29 bound in the active site (PDB entry 1GU1, $1.8 \AA$, [42]), inspired the structure-based design of new compounds with improved inhibition properties. Specifically, the 3-substituted cyclohexene derivatives 31-36, the tetrahydrobenzothiophene derivatives 37 , the $O$-alkyl derivatives $\mathbf{3 8}$, and the 2,3-disubstituted compounds $\mathbf{3 9}$ were reported (Fig. 9) [54-71]. A summary of the inhibition constants of these compounds against Mt-DHQ2 and $H p$-DHQ2 are shown in Tables $\mathbf{1}$ and $\mathbf{2}$.

The idea of adding substituents at the $\mathrm{C} 3$ position arose from the X-ray crystal structure of the $S c$-DHQ2/29 binary complex (PDB entry 1GU1) reported by Roszak et al. [42]. In the active site of this structure it was observed that, in addition to 29, a molecule each of glycerol and tartrate, originating from the enzyme storage buffer, were present at distances of $3.7 \AA$ and $4.6 \AA$ from the inhibitor 29 , respectively. This suggested the existence of additional positions in the vicinity of $\mathbf{2 9}$ that could be used to enhance the binding affinity of the enzyme by the inhibitor. In particular, the incorporation at the $\mathrm{C} 3$ position of $\mathbf{2 9}$ of groups that could interact with the residue triggers the formation of the enolate intermediate 26, the tyrosine. This possibility was first studied by incorporation of aromatic rings at the $\mathrm{C} 3$ position in 29 in order to establish $\pi$-stacking interactions with the tyrosine ring. These studies led to the discovery of the most potent inhibitor at that time against any DHQ2, the 3nitrophenyl derivative 32.7, with a $K_{\mathrm{i}}$ value of $54 \mathrm{nM}$ (against $M t$-DHQ2) [54,55]. At that time a crystal structure of $M t$-DHQ2 with a full description of the substrate-covering loop in which the essential tyrosine and arginine are located was not available and NMR studies [Saturation Transfer Difference (STD) and 1D and 2D-TR-NOESY experiments) were performed to determine its binding mode [56]. These studies showed that only one of the conformations existing in solution for this inhibitor is selected when bound to the active site of $M t$-DHQ2. In the bound state, the 3-nitrophenyl unit of the potent inhibitor 32.7 is frozen in one orientation relative to the cyclohexene ring, with the nitro group orientated towards double bond side. In this arrangement, the nitro group establishes a strong $\pi$-stacking interaction with the phenol group of the essential tyrosine. These initial results were very important in highlighting that the incorporation of aromatic rings at $\mathrm{C} 3$ improves dramatically the inhibitory potency and resulted in numerous subsequent structure-based studies to improve this activity further.

Another result of these investigations was the resolution of several crystal structures of diverse enzyme-inhibitor complexes that have been instrumental in gaining a deep understanding of the role of the substituents in the cyclohexene core of 29. Among them, it is worth noting two crystal structures of $M t$-DHQ2 solved at $1.5 \AA$. The first one is the structure with a 2,3-disubstituted compound $39(\mathbf{3 9 . 8}, \mathrm{Ar}=$ benzo $[b]$ thiophen-2-yl; ${ }^{2} \mathrm{R}=$ methylthien-2-yl) (PDB entry $2 \mathrm{Y} 77$ ) bound in the active site (Fig. 10A) [66]. This structure revealed that the 2,3-disubstituted compounds might inhibit the enzyme by a double effect. Thus, as for 2-benzyl derivative $\mathbf{2 8 b}$ in PDB entry $2 \mathrm{XB} 8$, the aromatic moiety at $\mathrm{C} 3$ in the 2,3-disubstituted compounds blocks the entry of the essential arginine side chain into the active site. In addition, the benzyl substituent at $\mathrm{C} 2$ prevents the hydrogenbonding interaction of Arg 108 with the essential Tyr24 of the substrate-covering loop, i.e., the residue that initiates catalysis (Fig. 10A). These results suggest that compounds that are able to block the alignment between Tyr24 and Arg 108 would also be good competitive inhibitors of DHQ2 enzymes.

The second crystal structure that is worth highlighting is the one in complex with an $O$-alkyl derivative $38(\mathbf{3 8 . 2}, \mathrm{Ar}$ $=5$-methylbenzo $[b]$ thiophen-2-yl) (PDB entry 2Y71) bound in the active site [66]. This compound has $K_{\mathrm{i}}$ values of $42 \mathrm{nM}$ [66] and $130 \mathrm{nM}$ [63] against $M t$-DHQ2 and $H p$-DHQ2, respectively. As in PDB entry $2 \mathrm{Y}_{77}$, the essential arginine is out of the active site. More importantly, this structure reveals that the oxygen atom of the methyleneoxy spacer of the inhibitor is located $3.1 \AA$ away from WAT1 (Fig. 10B). This suggests that an important contribution to the high potency of inhibitors of these types is the interaction between the oxygen atom of the methyleneoxy spacer and WAT1 and this aspect should therefore be considered in the structure-based design of inhibitors. Indeed, the replacement of the oxygen atom of the methyleneoxy spacer of $\mathbf{3 8}$ by a carbon atom (ethylene spacer, compounds 36, [68]) leads to a decrease in the inhibition potency by up to 20 -fold. The inhibition data, together with the results of MD simulation studies, show that, in general, effects of the geometry and size of the alkyl spacer are more pronounced in the inhibition efficiency of the $H p$-DHQ2 enzyme. For both enzymes, compounds with a flexible spacer proved to be more potent than compounds with a more rigid one because it provides the necessary conformational flexibility for the aryl moiety to be accommodated in the active site in an extended conformation. Docking studies suggest that compounds with a three-carbon spacer fit more efficiently into the active site than the corresponding two-carbon spacer analogs because they locate the aromatic ring closer to the aliphatic residues of the enzyme active site. For instance, replacement of the ethylene spacer in $\mathbf{3 6 . 1}$ by a propylene one, compound 36.4, leads to a decrease in the inhibition potency by up to 4 -fold (Table $\mathbf{1}$ ). 
Table 1. Selected examples of reversible competitive inhibitors of DHQ2 enzymes. $K_{\mathrm{i}}(\mu \mathrm{M})$ values of compounds $29-37$ against $M t$ DHQ2 and $H p$-DHQ2 are shown.

\begin{tabular}{|c|c|c|c|c|c|c|c|c|c|}
\hline Compd & $\mathbf{G}$ & Mt-DHQ2 & Hp-DHQ2 & Ref & Compd & G & $M t$-DHQ2 & Hp-DHQ2 & Ref \\
\hline 29 & $\mathrm{H}$ & 200 & 370 & [51] & 32.20 & & 13.2 & -- & [57] \\
\hline 30 & $\mathrm{~F}$ & 10 & -- & [52] & 32.21 & & 0.83 & 4.85 & {$[55,57]$} \\
\hline 31 & $\mathrm{CO}_{2} \mathrm{H}$ & 0.94 & -- & {$[58]$} & 32.22 & & 0.59 & 1.8 & {$[55,57]$} \\
\hline 32.1 & & 1.5 & 7.4 & {$[55,57]$} & 32.23 & & 2.5 & 63 & [61] \\
\hline 32.2 & & 1.8 & 11 & {$[55,57]$} & 32.24 & & 3.75 & -- & [57] \\
\hline 32.3 & & 17 & 8.4 & {$[55,57]$} & 32.25 & & 0.85 & 1 & [61] \\
\hline 32.4 & & 1.5 & 9.4 & {$[55,57]$} & 32.26 & & 0.25 & 0.54 & [61] \\
\hline 32.5 & & 2.13 & 139 & {$[55,57]$} & 32.27 & & 3.7 & 4.6 & [61] \\
\hline 32.6 & & 95 & 128 & {$[55,57]$} & 32.28 & & 15 & $>400$ & [61] \\
\hline 32.7 & & 0.054 & 38.4 & {$[55,57]$} & 32.29 & & 0.018 & 1.0 & [61] \\
\hline 32.8 & & 150 & 150 & {$[55,57]$} & 32.30 & & 58 & 110 & [61] \\
\hline 32.9 & & 2.4 & 20.5 & {$[55,57]$} & 32.31 & & 0.74 & 0.49 & [59] \\
\hline 32.10 & & 45 & 56 & {$[55,57]$} & 32.32 & & 0.38 & 1.2 & [59] \\
\hline 32.11 & & 6.5 & 6.8 & {$[57]$} & 32.33 & & $>100$ & 24 & [59] \\
\hline 32.12 & & 1.9 & 141 & {$[57]$} & 32.34 & & 11 & 2.9 & [59] \\
\hline 32.13 & & 1.2 & 3.7 & {$[57]$} & 33.1 & & 0.91 & -- & {$[60]$} \\
\hline 32.14 & & 2.0 & 14.2 & {$[57]$} & 33.2 & & 8.7 & -- & [60] \\
\hline 32.15 & & 2.85 & 3.6 & [57] & 33.3 & & 49 & -- & [60] \\
\hline
\end{tabular}


(Table 1) contd....

\begin{tabular}{|c|c|c|c|c|c|c|c|c|c|}
\hline Compd & G & Mt-DHQ2 & Hp-DHQ2 & Ref & Compd & G & Mt-DHQ2 & Hp-DHQ2 & Ref \\
\hline 32.16 & & 0.97 & 7.1 & [57] & 33.4 & & 27 & -- & [58] \\
\hline 32.17 & & 0.85 & 8.1 & [57] & 34.1 & & 0.36 & 0.25 & [64] \\
\hline 32.18 & & $>300$ & -- & [57] & 34.2 & & 0.55 & 0.11 & [64] \\
\hline 32.19 & & 1.95 & -- & [57] & 34.3 & & 0.13 & 0.10 & [64] \\
\hline 34.4 & & 0.11 & 0.10 & [64] & 36.1 & & 0.44 & 0.79 & [68] \\
\hline 34.5 & & 2.19 & 0.71 & {$[64]$} & 36.2 & & 0.27 & 1.15 & {$[68]$} \\
\hline 34.6 & & 0.88 & 1.20 & [64] & 36.3 & & 0.25 & 2.46 & [68] \\
\hline 34.7 & & 0.19 & 0.32 & [64] & 36.4 & & 0.18 & 0.24 & [68] \\
\hline 34.8 & & 0.13 & 0.09 & [64] & 36.5 & & 0.07 & 0.29 & [68] \\
\hline 35.1 & & 0.78 & 1.40 & [68] & 37.1 & $\mathrm{H}$ & 3.0 & 34 & [65] \\
\hline 35.2 & & 0.52 & 3.11 & [68] & 37.2 & $\mathrm{Me}$ & 0.40 & 1.6 & [65] \\
\hline 35.3 & & 0.14 & -- & [60] & 37.3 & vinyl & 0.05 & 1.26 & [65] \\
\hline 35.4 & & 0.12 & -- & {$[60]$} & 37.4 & & 0.86 & 38 & [65] \\
\hline 35.5 & & 4.3 & -- & [60] & 37.5 & (E)-2-propenyl & 0.10 & 0.35 & [65] \\
\hline 35.6 & & $>100$ & -- & {$[60]$} & 37.6 & ethyl & 0.07 & 0.32 & [65] \\
\hline 35.7 & & 2.3 & -- & {$[60]$} & 37.7 & 1-propyl & 0.05 & 0.12 & {$[65]$} \\
\hline 35.8 & & 20 & -- & {$[60]$} & 37.8 & isopropyl & 0.19 & 3.4 & [65] \\
\hline 35.9 & & 105 & -- & [60] & 37.9 & & 0.11 & 1.08 & {$[65]$} \\
\hline 35.10 & & 17 & -- & {$[60]$} & $\mathbf{3 7 . 1 0}$ & & 0.09 & 0.60 & [65] \\
\hline
\end{tabular}


Table 2. Selected examples of reversible competitive inhibitors of DHQ2 enzymes. $K_{i}(n M)$ values of compounds 38-39 against $M t$ DHQ2 and $H p$-DHQ2 are shown.

\begin{tabular}{|c|c|c|c|c|c|}
\hline Compd & Ar & ${ }^{2} \mathbf{R}$ & Mt-DHQ2 & Hp-DHQ2 & Ref \\
\hline 38.1 & & $\mathrm{H}$ & 28 & 132 & {$[63,66]$} \\
\hline 38.2 & & $\mathrm{H}$ & 42.5 & 130 & {$[63,66]$} \\
\hline 38.3 & & $\mathrm{H}$ & 35 & 205 & {$[66]$} \\
\hline 38.4 & & $\mathrm{H}$ & 31 & 166 & {$[63,66]$} \\
\hline 38.5 & & $\mathrm{H}$ & 35 & 310 & {$[66]$} \\
\hline 38.6 & & $\mathrm{H}$ & 235 & 920 & {$[63,66]$} \\
\hline 39.1 & & & 40 & 97 & {$[66]$} \\
\hline 39.2 & & & 188 & 50 & {$[66]$} \\
\hline 39.3 & & & 1100 & 6700 & {$[66]$} \\
\hline 39.4 & & & 440 & 140 & {$[66]$} \\
\hline 39.5 & & & 6000 & 260 & {$[66]$} \\
\hline 39.6 & & & 5100 & 14600 & [66] \\
\hline 39.7 & & allyl & 1240 & 1100 & [66] \\
\hline 39.8 & & & 250 & 280 & [66] \\
\hline 39.9 & & & 870 & 279 & [66] \\
\hline 39.10 & & & 59 & 100 & [66] \\
\hline
\end{tabular}

Taking into account the important stabilizing contribution that the interaction between WAT1 and either enolate mimetics like compound $\mathbf{3 8}$, the natural substrate or the enolate intermediate $\mathbf{3 2}$ seem to have in their binding with the DHQ2 enzyme, the WAT1 binding pocket was also explored in the structure-based design of inhibitors of these enzymes [70]. This aspect was explored with compounds 4043 (Fig. 11).

The crystal structures of $M t-\mathrm{DHQ} 2$ in complex with compounds 40 (PDB entry 4CIV, $2.9 \AA$ ) and 41 (PDB entry 4CIW, $2.2 \AA$ ) show that, in the absence of the benzyl group, the hydroxyl group of the $\mathrm{C} 3$ side chain of these compounds does not interact with WAT1 and does not occupy the
WAT1 binding pocket. However, in the presence of the benzyl group in the $\mathrm{C} 3$ side chain, important differences in the binding mode interactions with WAT1 and the WAT1 binding pocket are observed (Fig. 12). The crystal structures of $M t$-DHQ2/42a (PDB entry 4CIX, $2.9 \AA$ ) and $M t$-DHQ2/43a (PDB entry 4CIY, $2.1 \AA$ ) binary complexes, along with the inhibition data and results of MD simulation studies with the corresponding chlorides $\mathbf{4 2} \mathrm{b}$ and $\mathbf{4 3 b}$, reveals that analogs with the $R$ configuration on the $\mathrm{C} 3$ side chain, which also bind to the active site with an extended conformation of this chain, are more potent because, in this arrangement, they promote interactions with WAT1 and the residues located within this pocket. More importantly, the binding affinity is reduced if the ligands occupy the WAT1 binding pocket. 
A

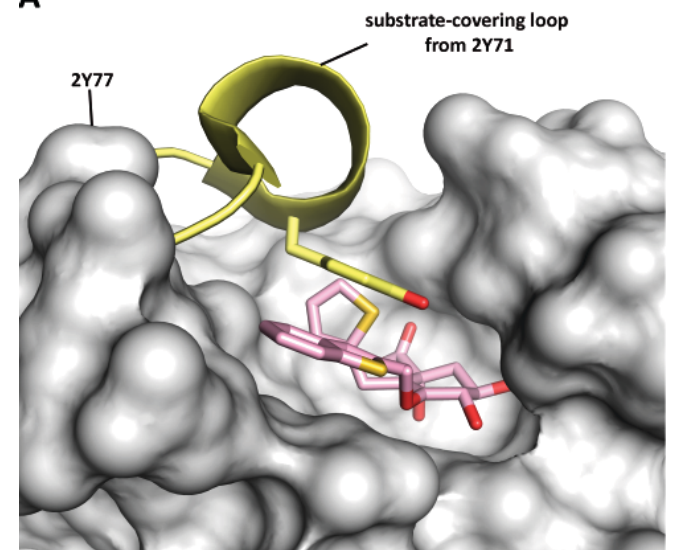

B

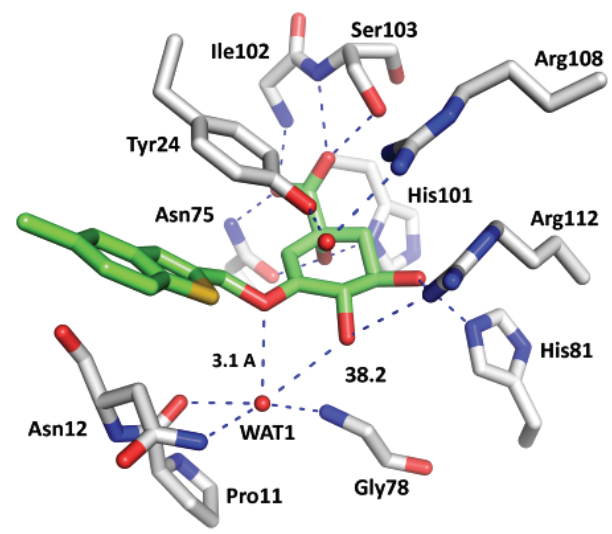

Fig. (10). A) Overlapping of the crystal structure of $M t$-DHQ2 (gray) with a 2,3-disubstituted compound (39.8, pink) in the active site (PDB entry $2 \mathrm{Y} 77,1.5 \AA$ ) with the substrate-covering loop (closed form) of $M t$-DHQ2/28b binary complex (PDB entry 2XB8). B) Interactions of the $O$-alkyl derivative $38\left(\mathbf{3 8 . 2},{ }^{1} \mathrm{R}=5\right.$-methylbenzo[b]thiophen-2-yl) with $M t$-DHQ2 (PDB entry 2 Y71, 1.5 $\AA$ ). Polar interactions between the ligand, WAT1 and Mt-DHQ2 are shown as blue dashed lines. WAT1 and relevant residues are shown and labeled.<smiles>O=C(O)[C@]1(O)C=C(CO)C[C@@H](O)[C@H]1O</smiles>

$40 \mathrm{n}=1$

$41 \mathrm{n}=2$

\begin{tabular}{lrrr} 
& $\mathbf{4 0 / 4 1}$ & $\mathbf{4 2 a} / \mathbf{4 2} \mathbf{b}$ & $\mathbf{4 3 a} / \mathbf{4 3} \mathbf{b}$ \\
\cline { 2 - 4 }$H p$-DHQ2 & $282 / 188$ & $37 / 40.5$ & $33 / 10.5$ \\
Mt-DHQ2 & $11.2 / 15.0$ & $34 / 14.5$ & $27 / 0.5$
\end{tabular}

Fig. (11). Designed mimetics of the enolate intermediate 26 to explore the WAT1 binding pocket of the DHQ2 enzymes. $K_{\mathrm{i}}(\mu \mathrm{M})$ values for compounds 40-43 against $H p$ - and $M t$-DHQ2 enzymes are shown.

The binding requirements of the DHQ2 active site, particularly regarding the carboxylate binding pocket, which is a key part in the enzyme recognition, has been a major challenge in order to achieve optimal in vitro antibacterial activity, especially in the anti-tubercular case. However, an ester prodrug approach proved to improve permeability of the mycobacterial cell and therefore the antibacterial activity [66]. The stability of the ester proved to be crucial to achieve improved in vitro activities. In general, the activity dramatically increases with the stability of the ester. Propyl esters were the most potent of the series, with MIC values of 5 $\mu \mathrm{g} / \mathrm{mL}$. These initial results have been very important to prove that the DHQ2 enzyme is a good target for the development of novel antibiotics. However, further improvement of the prodrug approach is required to achieve the nanomolar activity obtained with the isolated enzyme.

In this context, and in the search for drug-like aromatic inhibitors of $M t$-DHQ2, several 3-nitrobenzylgallate-based analogs 44-46 with inhibitory activities in the micromolar range have recently been described [71,72] (Fig. 13).

\subsection{QSAR Studies}

The large number of inhibitors described and the available structural data have allowed the development of QSAR models for the $H p$-DHQ2 and $M t$-DHQ2 enzymes and these aid in rationalizing the determinants of binding affinity and in understanding the differences between the two enzymes. Thus, comparative binding energy (COMBINE) analysis allowed quantification of the contribution of each active site residue to inhibition of the two enzymes [73].

For $\mathrm{Hp}$-DHQ2, these QSAR studies identified the van der Waals interactions with Asn10, Met13, Leu14, Tyr22, Leu103, His 102 and Gly78, and Gln63* and Ala90* of a symmetry-related neighboring subunit, as well as the electrostatic and hydrogen bonding interactions with the WAT1 water molecule, as those that contribute most significantly to explaining the differences in inhibitory potency [74]. For MtDHQ2, the QSAR model is dominated by van der Waals interactions with active site residues Tyr24, Leu13, Leu16, Ile102, Gly77, Asn75 and His101, and with Ala91* and Glu92* of the neighboring subunit, as well as by interactions with the WAT1 water molecule and the crystallographic water molecule close to Arg108 and Tyr24. In general, the key binding interactions of the inhibitors with the enzymes can be organized into five key pockets: (1) the substrate-covering loop (Tyr); (2) the interface between chains; (3) the WAT1 binding pocket; (4) the $\mathrm{C} 2$ binding pocket; and (5) the $\mathrm{C} 1$ binding pocket. For both enzymes, it is worth noting the crucial contribution of the ligand interactions with the WAT1 water molecule and with the interface pocket close to the active site, which are responsible for significant differences between the two enzymes. In particular, for $\mathrm{Hp}$-DHQ2 these studies suggested that enzyme inhibition might be enhanced by promoting interactions between the ligand and residues located at the 'bottom' of the interface, and avoiding contacts with residues located at the 'upper part' of the interface. For Mt-DHQ2, improving the van der Waals interactions with residues located at the entrance to the interface might provide more potent inhibitors. For both enzymes, extending the contacts with the essential aspartate would be unfavorable.

\section{CONCLUSION}

Despite the recognized need for new antibiotics, only two new classes have been brought to the market in the last three 


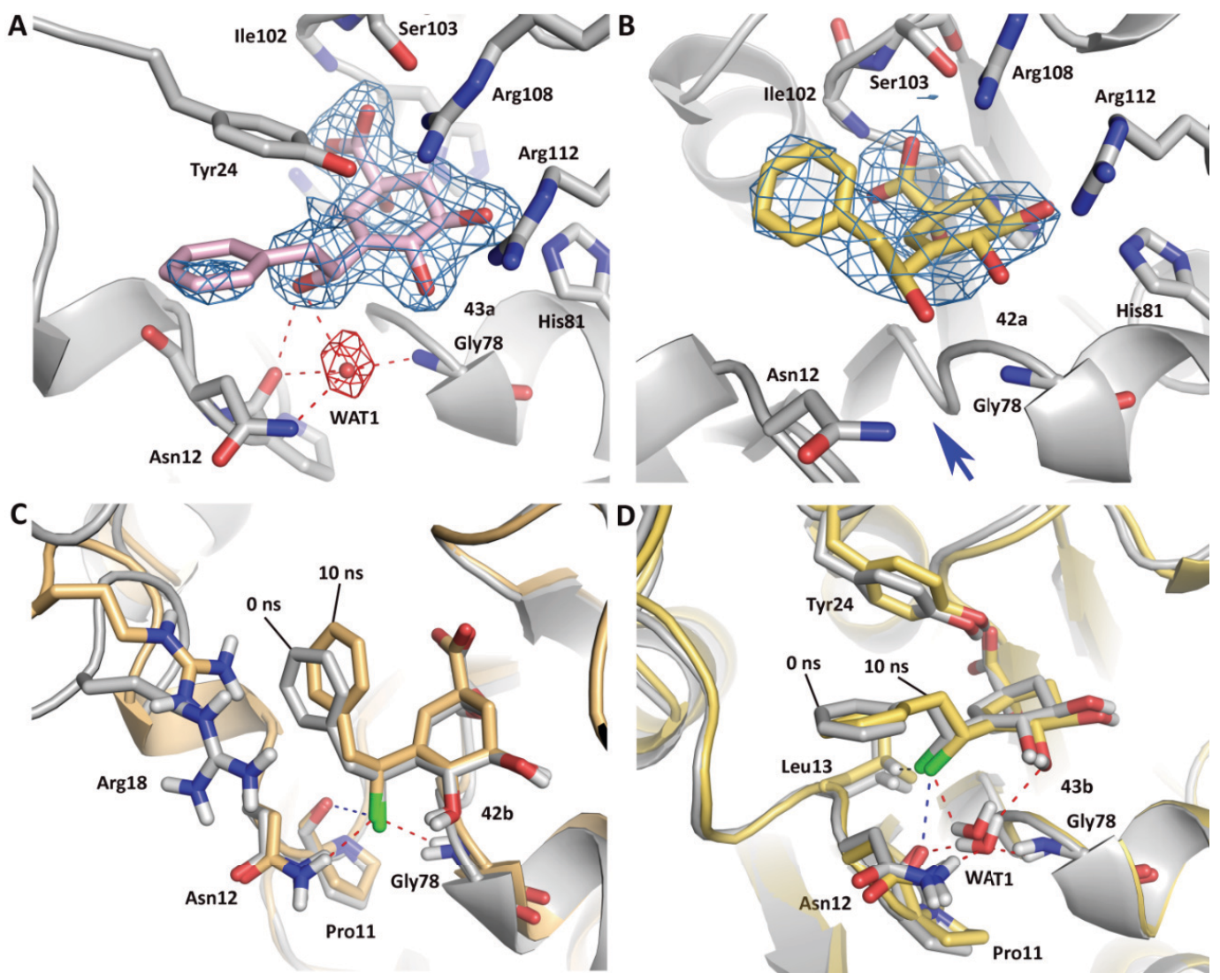

Fig. (12). Binding interactions of inhibitors 42 and 43 with WAT1 and the WAT1 binding pocket of Mt-DHQ2 obtained by X-ray crystallography and MD simulation studies. A) Binary complex $M t$-DHQ2/43a (PDB entry 4CIY, $2.1 \AA$ ). B) Binary complex $M t$-DHQ2/42a (PDB entry 4CIX, $2.9 \AA$ ). C,D) Comparison of the binding mode of $S$-chloride $\mathbf{4 2 b}(\mathrm{C})$ and $R$-chloride $43 \mathbf{b}$ after minimization and prior simulation (gray) and after $10 \mathrm{~ns}$ of dynamic simulation (light orange and yellow, respectively). Relevant hydrogen-bonding (red), halogen-bonding (blue) and $\mathrm{CH}$....Cl interactions (black) are shown.

decades. Besides this alarming trend, research into the discovery of new drugs by large pharmaceutical companies has dwindled. Hence, there is great interest in the development of alternative therapies, in particular the identification of new therapeutic targets and the discovery of compounds that target them. In fact, many antibiotics that are highly successful in human clinical use inhibit only a few essential processes for bacterial survival. In this context, the enzymes involved in the biosynthesis of aromatic amino acids are recognized as attractive targets for antibiotic drug discovery because they are essential in many pathogenic bacteria but are absent in mammals. It is therefore not surprising that, in recent years, the enzymes involved in this pathway have attracted a great deal of attention, particularly shikimate kinase and type II dehydroquinase, for the discovery of new anti-tubercular drugs and novel treatments for infections caused by Helicobacter pylori bacterium.

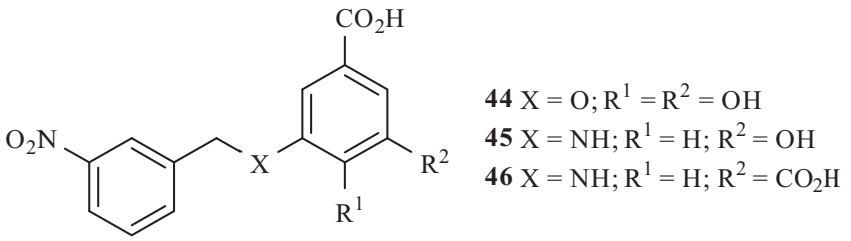

Fig. (13). Selected examples of drug-like aromatic inhibitors of $M t$ DHQ2.
Several selective inhibitors of these enzymes have been developed based on the mechanism of action of these enzymes and the available crystal structures. Most of the developed inhibitors are either analogs of the natural substrate recognized by the enzyme or mimetics of the reaction intermediate catalyzed by them. Some examples of inhibitors identified by screening have also been described. This success has benefitted from very important biochemical and structural studies and from the computational calculations performed with the solved crystal structures. These studies have provided an in-depth knowledge of the reaction mechanism and the determinants of binding affinity for these inhibitors. The examples summarized in this review show that, in both cases, those compounds that are able to reduce the flexibility of the substrate-covering loop, which is essential for catalytic turnover, is a good strategy for inhibition. For the DHQ2 enzyme, those compounds that are able to disturb the catalytic arrangement of the essential tyrosine and arginine are very potent inhibitors. Thus, potent inhibitors are afforded by avoiding the entrance into the active site of the arginine side chain or blocking its cation- $\pi$ interaction with the tyrosine phenol group. Another efficient strategy is either preventing the hydrogen-bonding interaction of the tyrosine with the conserved Arg108 (in Mt-DHQ2) of the active site or establishing a $\pi$-stacking interaction with the tyrosine side chain. Moreover, the interaction of the aromatic group of the 
inhibitors with the interface between chains is responsible for the different inhibition potency against the two DHQ2 enzymes and this is crucial to achieve high affinity ligands.

The most challenging issue in targeting the enzymes of this pathway is the high polarity of the inhibitors, mainly due to the carboxylate recognition that is required for good binding affinity. This makes it difficult to achieve good delivery of the inhibitors inside the cells. However, the fact that an ester prodrug approach proved to improve permeability into the mycobacterial cell, which is a Gram-positive bacterium but with characteristics of the Gram-negative ones due to the peptidoglycan layer in its cell wall, to provide optimal MIC values is highly encouraging. This finding has opened the door for the future development of new and more effective ways to deliver these inhibitors inside the cell. More importantly, it has proved that these enzymes are good targets for the development of inhibitors that can be used as drugs.

\section{CONFLICT OF INTEREST}

The authors confirm that this article content has no conflict of interest.

\section{ACKNOWLEDGEMENTS}

Financial support from the Spanish Ministry of Science and Innovation (SAF2013-42899-R), Xunta de Galicia (GRC2013-041) and the European Regional Development Fund (ERDF) is gratefully acknowledged.

\section{REFERENCES}

[1] Cosgrove, S.E.; Carmeli, Y. The impact of antimicrobial resistance on health and economic outcomes. Clin. Infect. Dis., 2003, 36, 1433-1437.

[2] Zaoutis, T.E. Antibiotic resistance: who will pay the bills?. Clin. Infect. Dis., 2009, 49, 1185-1186.

[3] Cornaglia, G. Fighting infections due to multidrug-resistant Grampositive pathogens. Clin. Microbiol. Infect., 2004, 10 (Supp. 4), 18-22.

[4] Koul, A.; Arnoult, E.; Lounis, N.; Guillemont, J.; Andries, K. The challenge of new drug discovery for tuberculosis. Nature, 2011, 469, 483-490.

[5] Butler, D. New fronts in an old war. Nature, 2000, 406, 670-672.

[6] Morens, D.M.; Folkers, G.K.; Fauci, G.K. The challenge of emerging and re-emerging infectious diseases. Nature, 2004, 430, 242249.

[7] Moir, D.T.; Shaw, K.J.; Hare, R.S.; Vovis, G.F. Genomics and antimicrobial drug discovery. Antimicrob. Agents Chem., 1999, 43, 439-446.

[8] Swartz, M.N. Hospital-acquired infections: diseases with increasingly limited therapies. Proc. Natl. Acad. Sci. USA, 1994, 91, 2420-2427.

[9] Abell, C. Enzymology and Molecular Biology of the Shikimate Pathway, In: Comprehensive Natural Products Chemistry; Sankawa, U. Ed.; Pergamon, Elsevier Science Ltd.: Oxford, 1999; Vol 1, pp. 573-607.

[10] Lamichhane, G.; Freundlich, J.S.; Ekins, S.; Wickramaratne, N.; Nolan, S.T.; Bisha, W.R. Essential metabolites of Mycobacterium tuberculosis and their mimics. Mbio, 2011, 2, e00301-10.

[11] Roberts, F.; Roberts, C.W.; Johnson, J.J.; Kyle, D.E.; Krell, T.; Coggins, J.R.; Coombs, G.H.; Milhous, W.K.; Tzipori, S.; Ferguson, D.J.; Chakrabarti, D.; McLeod, R. Evidence for the shikimate pathway in apicomplexan parasites. Nature, 1998, 393, 801-805.

[12] Campbell, S.A.; Richards, T.A.; Mui, E.J.; Samuel, B.U.; Coggins, J.R.; McLeod, R.; Roberts, C.W. Evidence for the shikimate pathway in apicomplexan parasites. Int. J. Parasit., 2004, 34, 5-13.

[13] McConkey G.A.; Pinney J.W.; Westhead D.R.; Plueckhahn K.; Fitzpatrick T.B.; Macheroux P.; Kappes, B. Annotating the Plas- modium genome and the enigma of the shikimate pathway. Trends Parasitol., 2004, 20, 60-65.

[14] Sikorski, J.A.; Gruys, K.J. Interaction of the herbicide glyphosate with its target enzyme 5-enolpyruvylshikimate 3-phosphate synthase in atomic detail. Acc. Chem. Res., 1997, 30, 2-8.

[15] Schönbrunn, E.; Eschenburg, S.; Shuttleworth, W.A.; Schloss, J.V.; Amrhein, N.; Evans, J.N.S.; Kabsch, W. Interaction of the herbicide glyphosate with its target enzyme 5-enolpyruvylshikimate 3phosphate synthase in atomic detail. Proc. Natl. Acad. Sci. USA, 2001, 98, 1376-1380.

[16] Funke, T.; Han, H.; Healy-Fried, M. L.; Fischer, M.; Schönbrunn, E. Molecular basis for the herbicide resistance of Roundup Ready crops. Proc. Natl. Acad. Sci. USA, 2006, 103, 13010-13015.

[17] Data base for essential genes: http:/www.essentialgene.org/

[18] De María, N.; Becerril, J.M.; García-Plazaola, J.I.; Hernández, A.; De Felipe, M.R.; Fernández-Pascual, M. New insights on glyphosate mode of action in nodular metabolism: role of shikimate accumulation. J. Agric. Food Chem., 2006, 54, 2621-2628.

[19] Chen, K.; Dou, J.; Tang, S.; Yang, Y.; Wang, H.; Fang, H.; Zhou, C. Deletion of the aroK gene is essential for high shikimic acid accumulation through the shikimate pathway in E. coli. Bioresour. Technol., 2012, 119, 141-147.

[20] Hartmann, M.D.; Bourenkov, G.P.; Oberschall, A.; Strizhov, N.; Bartunik, H.D. Mechanism of phosphoryl transfer catalyzed by shikimate kinase from Mycobacterium tuberculosis. J. Mol. Biol., 2006, 364, 411-423.

[21] Krell, T.; Maclean, J.; Boam, D.J.; Cooper, A.; Resmini, M.; Brocklehurst, K.; Kelly, S.M.; Price, N.C.; Lapthorn, A.J.; Coggins, J.R. Biochemical and X-ray crystallographic studies on shikimate kinase: the important structural role of the P-loop lysine. Protein Sci., 2001, 10, 1137-1149.

[22] Dhaliwal, B.; Nichols, C.E.; Ren, J.; Lockyer, M.; Charles, I.; Hawkins, A.R.; Stammers, D.K. Crystallographic studies of shikimate binding and induced conformational changes in Mycobacterium tuberculosis shikimate kinase. FEBS Lett., 2004, 574, 49-54.

[23] Dias, M.V.; Faim, L.M.; Vasconcelos, I.B.; de Oliveira, J.S.; Basso, L.A.; Santos, D.S.; de Azevedo, W.F. Effects of the magnesium and chloride ions and shikimate on the structure of shikimate kinase from Mycobacterium tuberculosis. Acta Cryst., 2007, F63, $1-6$.

[24] Gu, Y.; Reshentnikova, L.; Li, Y.; Wu, Y.; Yan, H.; Singh, S.; Ji, X. Crystal structure of shikimate kinase from Mycobacterium tuberculosis reveals the dynamic role of the LID domain in catalysis. J. Mol. Biol., 2002, 319, 779-789.

[25] Blanco, B.; Prado, V.; Lence, E.; Otero, J.M.; García-Doval, C.; van Raaij, M.J.; Llamas-Saiz, A.L.; Lamb, H.; Hawkins, A.R.; González Bello, C. Mycobacterium tuberculosis shikimate kinase inhibitors: design and simulation studies of the catalytic turnover. J. Am. Chem. Soc., 2013, 135, 12366-12376.

[26] Simithy, J.; Reeve, N.; Hobrath, J.V.; Reynolds, R.C. Identification of shikimate kinase inhibitors among anti-Mycobacterium tuberculosis compounds by LC-MS. Tuberculosis, 2014, 94, 152-158.

[27] Bandodkar, B.S.; Schmitt, S. Pyrazolone derivatives for the treatment of tuberculosis. WO/2007/020426 A1. February 22, 2007.

[28] H an, C.; Zhang, J.; Chen, L.; Chen, K.; Shen, X.; Jiang, H. Discovery of Helicobacter pylori shikimate kinase inhibitors: bioassay and molecular modeling. Bioorg. Med. Chem., 2007, 15, 656-662.

[29] Cheng, W.-C.; Chen, Y.-F.; Wang, H.-J.; Hsu, K.-C.; Lin, S.-C.; Chen, T.-J.; Yang, J.-M., Wang, W.-C. Structures of Helicobacter pylori shikimate kinase reveal a selective inhibitor-induced-fit mechanism. PLoS ONE, 2012, 7, e33481.

[30] Segura-Cabrera, A.; Rodríguez-Pérez, M.A. Structure-based prediction of Mycobacterium tuberculosis shikimate kinase inhibitors by high-throughput virtual screening. Bioorg. Med. Chem. Lett., 2008, 18, 3152-3157.

[31] Coracini, J.D.; de Azevedo, W.F. Shikimate kinase, a protein target for drug design. Curr. Med. Chem., 2014, 21, 592-604.

[32] Kleanthous, C.K.; Deka, R.; Davis, K.; Kelly, S.M.; Cooper, A.; Harding, S.E.; Price, N.C.; Hawkins, A.R.; Coggins, J.R. A comparison of the enzymological and biophysical properties of two distinct classes of dehydroquinase enzymes. Biochem. J., 1992, 282, 687-695.

[33] Gourley, D.G., Shrive, A.K.; Polikarpov, I.; Krell, T.; Coggins, J.R.; Hawkins, A.R.; Isaacs, N.W.; Sawyer, L. The two types of 3dehydroquinase have distinct structures but catalyze the same overall reaction. Nat. Struct. Biol., 1999, 6, 521-525. 
[34] Tacket, C.O.; Hone, D.M.; Curtiss III, R.; Kelly, S.M.; Losonsky, G.; Guers, L.; Harris, A.M.; Edelman, R.; Levine, M.M. Comparison of the safety and immunogenicity of $\triangle a r o \mathrm{C} \Delta a r o \mathrm{D}$ and $\Delta$ cya $\Delta$ crp Salmonella typhi strains in adult volunteers. Infect. Immun., 1992, 60, 536-541.

[35] Karnell, A.; Cam, P.D.; Verma, N.; Lindberg, A.A. AroD deletion attenuates Shigella flexneri strain $2457 \mathrm{~T}$ and makes it a safe and efficacious oral vaccine in monkeys. Vaccine, 1993, 11, 830-836.

[36] Tacket, C.O.; Hone, D.M.; Losonsky, G.; Guers, L.; Edelman, R.; Levine, M.M. Clinical acceptability and immunogenicity of CVD 908 Salmonella typhi vaccine strain. Vaccine, 1992, 10, 443-446.

[37] Racz, R.; Chung, M.; Xiang, Z.; He, Y. Systematic annotation and analysis of "virmugens"-virulence factors whose mutants can be used as live attenuated vaccines. Vaccine, 2013, 31, 797-805.

[38] Harris, J.; Kleanthous, C.; Coggings, J. R.; Hawkins, A.R.; Abell, C. Different mechanistic and stereochemical courses for the reactions catalysed by type I and type II dehydroquinases. J. Chem. Soc., Chem. Commun., 1993, 10, (4), 1080-1081.

[39] Krell, T.; Pitt, A.R.; Coggins, J.R. The use of electrospray mass spectrometry to identify an essential arginine residue in type II dehydroquinases. FEBS Lett., 1995, 360, 93-96.

[40] Krell, T.; Horsburgh, M.J.; Cooper, A.; Kelly, S.M.; Coggins, J.R. Localization of the active site of type II dehydroquinases. Identification of a common arginine-containing motif in the two classes of dehydroquinases. J. Biol. Chem., 1996, 271, 24492-24497.

[41] Harris, J.; González-Bello, C.; Kleanthous, C.; Coggins, J.R.; Hawkins, A.R.; Abell, C. Evidence from kinetic isotope studies for an enolate intermediate in the mechanism of type II dehydroquinases. Biochem. J., 1996, 319, 333-336.

[42] Roszak, A. W., Robinson, D.A.; Krell, T.; Hunter, I.S.; Frederickson, M.; Abell, C.; Coggins, J.R.; Lapthorn, A.J. The structure and mechanism of the type II dehydroquinase from Streptomyces coelicolor. Structure, 2002, 10, 493-503.

[43] Blomberg, L.M.; Mangold, M.; Mitchell, J.B.O.; Blumberger, J. Theoretical study of the reaction mechanism of Streptomyces coelicolor type II dehydroquinase. J. Chem. Theory Comput., 2009, 5, 1284-1294.

[44] Coderch, C.; Lence, E.; Peón, A.; Lamb, H.; Hawkins, A.R.; Gago, F.; González-Bello, C. Mechanistic insight into the reaction catalysed by bacterial type II dehydroquinases. Biochem. J., 2014, 458, 547-557.

[45] González-Bello, C.; Castedo, L. Progress in type II dehydroquinase inhibitors: from concept to practice. Med. Res. Rev., 2007, 27, 177208.

[46] Yao, Y.; Li, Z.-S. Structure-and-mechanism-based design and discovery of type II Mycobacterium tuberculosis dehydroquinate dehydratase inhibitors. Curr. Top. Med. Chem., 2014, 14, 51-63.

[47] González-Bello, C.; Prazeres, V.F.V.; Sánchez-Sixto, C.; Paz, S.; Tizón, L., Competitive Inhibitors of Type II Dehydroquinase Enzyme. WO2010/072813 A1. December 23, 2008.

[48] Prazeres, V.F.V.; Castedo, L.; Lamb, H.; Hawkins, A.R.; GonzálezBello, C. 2-substituted-3-dehydroquinic acids as potent competitive inhibitors of type II dehydroquinase. ChemMedChem, 2009, 4, 1980-1984.

[49] Peón, A.; Otero, J.M.; Tizón, L.; Prazeres, V.F.V.; Llamas-Saiz, A.L.; Fox, G.C.; van Raaij, M.J.; Lamb, H., Hawkins, A.R.; Gago, F.; Castedo, L.; González-Bello, C. Understanding the key factors that control the inhibition of type II dehydroquinase by $(2 R)-2$ benzyl-3-dehydroquinic acids. ChemMedChem, 2010, 5, 17261733.

[50] Lence, L.; Tizón, L.; Otero, J.M.; Peón, A.; Prazeres, V.F.V.; Llamas-Saiz, A.L.; Fox, G.C.; van Raaij, M.J.; Lamb, H.; Hawkins, A.R.; González-Bello, C. Mechanistic basis of the inhibition of type II dehydroquinase by (2S)- and (2R)-2-benzyl-3dehydroquinic acids. ACS Chem. Biol., 2013, 8, 568-577.

[51] Frederickson, M.; Parker, E.J.; Hawkins, A.R.; Coggins, J.R.; Abell, C. Selective Inhibition of Type II Dehydroquinases. J. Org. Chem., 1999, 64, 2612-2613.

[52] Frederickson. M.; Coggins, J.R.; Abell, C. Vinyl fluoride as an isoelectronic replacement for an enolate anion: inhibition of type II dehydroquinases. Chem. Commun., 2002, 1886-1887.

[53] Frederickson. M.; Roszak, A.W.; Coggins, J.R.; Lapthorn, A.J.; Abell, C. $(1 R, 4 S, 5 R)$-3-Fluoro-1,4,5-trihydroxy-2-cyclohexene-1carboxylic acid: the fluoro analogue of the enolate intermediate in the reaction catalyzed by type II dehydroquinases. Org. Biomol. Chem., 2004, 2, 1592-1596.
[54] González-Bello, C.; Lence, E.; Toscano, M.D.; Castedo, L.; Coggins, J.R.; Abell, C. Parallel solid-phase synthesis and evaluation of inhibitors of Streptomyces coelicolor type II dehydroquinase. $J$. Med. Chem., 2003, 46, 5735-5744.

[55] Sánchez-Sixto, C.; Prazeres, V.F.V.; Castedo, L.; Lamb, H.; Hawkins, A.R.; González-Bello, C. Structure-based design, synthesis, and biological evaluation of inhibitors of Mycobacterium tuberculosis type II dehydroquinase. J. Med. Chem. 2005, 48, 4871-4881

[56] Prazeres, V.F.V.; Sánchez-Sixto, C.; Castedo, L.; Canales, A.; Cañada, F.J.; Jiménez-Barbero, J.; Lamb, H.; Hawkins, A.R.; C. González-Bello, C. Determination of the bound conformation of a competitive nanomolar inhibitor of mycobacterium tuberculosis type II dehydroquinase by NMR spectroscopy. ChemMedChem, 2006, 1, 990-996.

[57] Prazeres, V.F.V.; Sánchez-Sixto, C.; Castedo, L.; Lamb, H.; Hawkins, A.R.; Riboldi-Tunnicliffe, A.; Coggins, J.R.; Lapthorn, A.J.; González-Bello, C. Nanomolar competitive inhibitors of Mycobacterium tuberculosis and Streptomyces coelicolor type II dehydroquinase. ChemMedChem, 2007, 2, 194-207.

[58] Toscano, M.D.; Payne, R.J.; Chiba, A.; Kerbarh, O.; Abell, C. Nanomolar inhibition of type II dehydroquinase based on the enolate reaction mechanism. ChemMedChem, 2007, 2, 101-112.

[59] Payne, R.J.; Riboldi-Tunnicliffe, A.; Kerbarh, O.; Abell, A.D.; Lapthorn, A.J.; Abell, C. Design, synthesis, and structural studies on potent biaryl inhibitors of type II dehydroquinases. ChemMedChem, 2007, 2, 1010-1013.

[60] Payne, R.J.; Peyrot, F.; Kerbarh, O.; Abell, A.D.; Abell, C. Rational design, synthesis, and evaluation of nanomolar type II dehydroquinase inhibitors. ChemMedChem, 2007, 2, 1015-1029.

[61] Sánchez-Sixto, C.; Prazeres, V.F.V.; Castedo, L.; Shuh, S.W.; Lamb, H.; Hawkins, A.R.; Cañada, F.J.; Jiménez-Barbero, J.; González-Bello, C. Competitive inhibitors of Helicobacter pylori type II dehydroquinase: synthesis, biological evaluation, and NMR studies. ChemMedChem, 2008, 3, 756-770.

[62] Tran, A.T.; Cergol, K.M.; Britton, W.J.; Bokhari, S.A.I.; Ibrahim, M.; Lapthorn, A.J.; Payne, R.J. Rapid assembly of potent type II dehydroquinase inhibitors via "Click" chemistry. Med. Chem. Commun., 2010, 1, 271-275.

[63] Prazeres, V.F.V.; Tizón, L.; Otero, J.M.; Guardado-Calvo, P.; Llamas-Saiz, A.L.; van Raaij, M.J.; Castedo, L.; Lamb, H.; Hawkins, A.R.; González-Bello, C. Synthesis and biological evaluation of new nanomolar competitive inhibitors of Helicobacter pylori type II dehydroquinase. Structural details of the role of the aromatic moieties with essential residues. J. Med. Chem. 2010, 53, 191-200.

[64] Tran, A.T.; Cergol, K.M.; West, N.P.; Randall, E.J.; Britton, W.J.; Bokhari, S.A.; Ibrahim, M.; Lapthorn, A.J.; Payne, R.J. Synthesis and evaluation of potent ene-yne inhibitors of type II dehydroquinases as tuberculosis drug leads. ChemMedChem, 2011, 6, 262265.

[65] Paz, S.; Tizón, L.; Otero, J.M.; Llamas-Saiz, A.L.; Fox, G.C.; van Raaij, M.J.; Lamb, H.; Hawkins, A.R.; Lapthorn, A.J.; Castedo, L.; González-Bello, C. Tetrahydrobenzothiophene derivatives: conformationally restricted inhibitors of type II dehydroquinase. ChemMedChem, 2011, 6, 266-272.

[66] Tizón, L.; Otero, J.M.; Prazeres, V.F.V.; Llamas-Saiz, A.L.; Fox, G.C.; van Raaij, M.J.; Lamb, H.; Hawkins, A.R.; Ainsa, J.A.; Castedo, L.; González-Bello, C. A prodrug approach for improving antituberculosis activity of potent Mycobacterium tuberculosis type II dehydroquinase inhibitors. J. Med. Chem., 2011, 54, 6063-6084.

[67] Dias, M.V.B.; Snee, W.C.; Bromfield, K.M.; Payne, R.J.; Palaninathan, S.K.; Ciulli, A.; Howard, N.I.; Abell, C.; Sacchettini, J.C.; Blundell, T.L. Structural investigation of inhibitor designs targeting 3-dehydroquinate dehydratase from the shikimate pathway of $M y$ cobacterium tuberculosis. Biochem. J., 2011, 436, 729-739.

[68] Blanco, B.; Sedes, A.; Peón, A.; Lamb, H.; Hawkins, A.R.; Castedo, L.; González-Bello, C. Synthesis of 3-alkyl enol mimics inhibitors of type II dehydroquinase: factors influencing their inhibition potency. Org. Biomol. Chem., 2012, 10, 3662-3676.

[69] Tran, A.T.; West, N.P.; Britton, W.J.; Payne, R.J. Elucidation of Mycobacterium tuberculosis type II dehydroquinase inhibitors using a fragment elaboration strategy. ChemMedChem 2012, 7, 10311043

[70] Blanco, B.; Sedes, A.; Peón, A.; Otero, J.M.; van Raaij, M.J.; Thompson, P.; Hawkins, A.R.; González-Bello, C. Exploring the water-binding pocket of the type II dehydroquinase enzyme in the 
structure-based design of inhibitors. J. Med. Chem., 2014, 57, 3494-3510.

[71] González-Bello, C.; Sánchez-Sixto, C.; Sedes, A.; Blanco, B. Ester Derivatives as Competitive Inhibitors of Type II Dehydroquinase Enzyme. WO2010/146125 A1. June 18, 2009.

[72] Schmidt, M.F.; Korb, O.; Howard, N. I.; Dias, M.V.B.; Blundell, T.L.; Abell, C. Discovery of Schaeffer's acid analogues as lead structures of Mycobacterium tuberculosis type II dehydroquinase using a rational drug design approach. ChemMedChem, 2013, 8, 54-58.
Howard, N. I.; Dias, M.V.B.; Peyrot, F.; Chen, L.; Schmidt, M.F.; Blundell, T.L.; Abell, C. Design and structural analysis of aromatic inhibitors of type II dehydroquinase from Mycobacterium tuberculosis. ChemMedChem, 2015, 10, 116-133.

[74] Peón, A.; Coderch, C.; Gago, F.; González-Bello, C. Comparative binding energy COMBINE analysis for understanding the binding determinants of type II dehydroquinase inhibitors. ChemMedChem, 2013, 8, 740-747. 